\title{
Ethylenediurea (EDU) spray effects on willows (Salix sachalinensis F. Schmid) grown in ambient or ozone-enriched air: implications for renewable biomass production
}

\author{
Evgenios Agathokleous ${ }^{1,2,3}\left(\right.$ Mitsutoshi Kitao $^{3} \cdot$ \\ Cong $\mathrm{Shi}^{4} \cdot$ Noboru Masui ${ }^{2} \cdot$ Shahenda Abu-ElEla ${ }^{5}$. \\ Kyohsuke Hikino $^{2,6} \cdot$ Fuyuki Satoh ${ }^{7}$ Takayoshi Koike ${ }^{2,8}$
}

Received: 28 July 2021 / Accepted: 1 September 2021 / Published online: 4 October 2021

(C) The Author(s) 2021

\begin{abstract}
Ground-level ozone $\left(\mathrm{O}_{3}\right)$ is a widespread air pollutant causing extensive injuries in plants. However, its effects on perennial energy crops remain poorly understood due to technical difficulties in cultivating fast-growing shrubs for biomass production under $\mathrm{O}_{3}$ treatment on the field. Here we present the results of a two-year evaluation in the framework of which willow (Salix sachalinensis F. Schmid) shrubs were exposed to ambient (AOZ) or elevated (EOZ) $\mathrm{O}_{3}$ in two successive growing seasons $(2014,2015)$ and treated with 0 (EDU0) or $400 \mathrm{mg} \mathrm{L}^{-1}$ (EDU400) ethylenediurea spray in the second growing season. In 2014, EOZ altered the chemical composition of both top young and fallen leaves, and a novel mechanism of decreasing
\end{abstract}

Project funding: This research was partly supported by grant \#201802 of the Japan's Forestry and Forest Products Research Institute (FFPRI) and KAKENHI grant \#JP17F17102 of the Japan Society for the Promotion of Science (JSPS). Evgenios Agathokleous was an International Research Fellow (ID No: P17102) of the JSPS, and JSPS is a non-profit, independent administrative institution.

The online version is available at http://www.springerlink.com.

Corresponding editor: Yu Lei.

Evgenios Agathokleous

evgenios@nuist.edu.cn; globalscience@frontier.hokudai.ac.jp

1 Department of Ecology, School of Applied Meteorology, Nanjing University of Information Science and Technology (NUIST), Nanjing 210044, People's Republic of China

2 School of Agriculture, Hokkaido University, Sapporo, Hokkaido 060-8589, Japan

3 Hokkaido Research Center, Forestry and Forest Products Research Institute (FFPRI), Sapporo 062-8516, Japan

4 School of Environmental Science and Engineering, Tiangong University, Tianjin 300387, People's Republic of China
$\mathrm{Mg}$ in fallen leaves while highly enriching it in young top leaves was revealed in shrubs exposed to EOZ. In 2015, EDU400 alleviated EOZ-induced decreases in leaf fresh mass to dry mass ratio (FM/DM) and leaf mass per area (LMA). While EDU400 protected against EOZ-induced suppression of the maximum rate at which leaves can fix carbon $\left(A_{\max }\right)$ in $\mathrm{O}_{3}$-asymptomatic leaves, it did not alleviate EOZ-induced suppression of the maximum rates of carboxylation $\left(V_{C \max }\right)$ and electron transport $\left(J_{\max }\right)$ and chlorophylls $a, b$, and $a+b$ in the same type of leaves. In $\mathrm{O}_{3}$-symptomatic leaves, however, EDU400 alleviated EOZinduced suppression of chlorophylls $a$ and $a+b$, indicating different mode of action of EDU between $\mathrm{O}_{3}$-asymptomatic and $\mathrm{O}_{3}$-symptomatic leaves. Extensive herbivory occurred only in AOZ-exposed plants, leading to suppressed biomass production, while EOZ also led to a similar suppression of biomass production (EDU0 $\times$ EOZ vs. EDU $400 \times$ EOZ). In 2016, carry-over effects were also evaluated following cropping and transplantation into new ambient plots. Effects of EOZ in the preceding growing seasons extended to the third growing season in the form of suppressed ratoon biomass production, indicating carry-over effect of EOZ. Although EDU400 protected against EOZ-induced suppression of

5 Department of Entomology, Faculty of Science, Cairo University, Giza 12613, Egypt

6 TUM School of Life Sciences, Technical University of Munich (TUM), Hans-Carl-von-Carlowitz Platz 2, 85354 Freising, Germany

7 Field Science Center for Northern Biosphere, Hokkaido University, Sapporo 060-0809, Japan

8 Research Center for Eco-Environmental Science, Chinese Academy of Science, Beijing 100085, People's Republic of China 
biomass production when applied in 2015 , there was no carry-over effect of EDU in the absence of EDU treatment in 2016. The results of this study provide novel mechanistic understandings of $\mathrm{O}_{3}$ and EDU modes of action and can enlighten cultivation of willow as energy crop.

Keywords Air pollution - Ethylenediurea (EDU) · Hormesis · Plant protection · Tropospheric ozone $\left(\mathrm{O}_{3}\right)$

\section{Introduction}

Willows (Salicaceae) have been an integral part of the human societies since the ancient times due to their multiple uses, such as the use of their bark to alleviate pain (Vlachojannis et al. 2009) and the utilization of their wood to create willow coracles, which dates back to Herodotus in the fifth century BC (Karp et al. 2011). Nowadays, fastgrowing willow (Salix spp.) clones are also cultivated in the framework of short-rotation forestry (Lumme and Tormala 1988), thus being important plants for cultivation as bioenergy crops throughout the world (Kopp et al. 2001; Adegbidi et al. 2001; Maruyama et al. 2002; Volk et al. 2006; MolaYudego and Pelkonen 2008; Mola-Yudego and GonzálezOlabarria 2010; El Kasmioui and Ceulemans 2012; Guidi Nissim et al. 2013; Fabio et al. 2017; Nordborg et al. 2018; Kakuk et al. 2021). Willow short rotation coppice is either fertilized or unfertilized, although unfertilized cultivations may produce less biomass, and there is a trade-off between a high annual net energy yield and a high ratio of gross energy yield to total primary energy input (Dimitriou et al. 2011; Guidi Nissim et al. 2013; Nordborg et al. 2018). Willows are also important components of water-saturated ecosystems (e.g. rivers) and urban green spaces (e.g. parks with ponds) (Niiyama 1987; Agathokleous et al. 2016b). Hence, willows play versatile roles of both ecological/environmental and anthropocentric importance, and their cultivation may further increase in the light of the recent carbon-neutral targets for the mid. part of the current century.

Ground-level ozone $\left(\mathrm{O}_{3}\right)$ is a secondary pollutant whose formation closely depends upon the levels of primary precursor pollutants, mainly NOx and volatile organic compounds (VOCs), under sunlight (Derstroff et al. 2017; Fenech et al. 2021; Liu et al. 2021; Querol et al. 2021). Due to its complex chemistry, the control of $\mathrm{O}_{3}$ levels is challenging, and $\mathrm{O}_{3}$ can remain at elevated concentrations even if the emissions of some $\mathrm{O}_{3}$ precursors are highly decreased (Sicard et al. 2020; Querol et al. 2021; Sicard 2021). Being also affected by transboundary long-range transport (Gao et al. 2020; Erickson et al. 2020), which downplays national efforts to decrease $\mathrm{O}_{3}$ concentrations, $\mathrm{O}_{3}$ levels may remain elevated for several decades to come (Sicard et al. 2017). Such elevated $\mathrm{O}_{3}$ levels can lead to inhibited photosynthesis and suppressed woody biomass production and yields (Paoletti 2006; Karnosky et al. 2007a; Koike et al. 2013; Jolivet et al. 2016; Li et al. 2017; Cotrozzi 2021), suggesting increased risks to tree productivity (Sicard et al. 2017; Feng et al. 2019a; Proietti et al. 2021; Sacchelli et al. 2021). Therefore, it is important to develop methodologies to protect plants against elevated $\mathrm{O}_{3}$-induced toxicity. However, it remains unknown whether elevated $\mathrm{O}_{3}$ suppresses the biomass production of shrub/tree energy crops cultivated on the field with no root limitation due to pot effect, yet such a root limitation would influence the response of plants to gaseous treatments (Oksanen 2003; Karnosky et al. 2007b; Wang et al. 2013).

Because of the suitability of Salix species, considerable genetic engineering targeted the development of clones with improved traits making them advantageous for biomass production, nutrient fitters, phytoremediation, and stabilization of stream banks (Kopp et al. 2001; Adegbidi et al. 2001). Genetic improvement of willows for biofuels and bioenergy has attracted much attention in the recent years (Maruyama et al. 2002; Volk et al. 2006; Karp et al. 2011; Fabio et al. 2017). For example, new triploid hybrids even displayed yields that are 19-27\% higher than commercial cultivars; yield is a major trait for genetic selection and biomass feedstock development (Fabio et al. 2017). However, for optimum cultivation as energy crops, breeding programs should consider that willows should be pest- and disease-free and their yield improvement should be achieved without increasing the demands for fertilizers and water (Karp et al. 2011). Therefore, innovative methodologies are needed to improve the performance of willows grown in an $\mathrm{O}_{3}$-polluted atmosphere without adding more fertilizers.

Ethylenediurea $\left(\mathrm{C}_{4} \mathrm{H}_{10} \mathrm{~N}_{4} \mathrm{O}_{2}\right.$; hereafter EDU) is a chemical compound that is known for its efficacy to act as both antiozonant, i.e. protecting materials against $\mathrm{O}_{3}$-induced damage, and phytoprotectant, i.e. protecting plants against $\mathrm{O}_{3}$-induced toxicity (Manning et al. 2011). It has been applied in research programs as protectant against $\mathrm{O}_{3}$-induced phytotoxicity for over 40 years, thus, it is the most widely studied substance for its capacity to protect a wide variety of plants against $\mathrm{O}_{3}$-induced toxicity (Paoletti et al. 2009; Feng et al. 2010; Oksanen et al. 2013; Agathokleous et al. 2015, 2021a). As a hormesis-inducing agent (Agathokleous et al. 2021a), EDU has been found to improve diverse traits of structure and function, including photosynthesis, chlorophyll fluorescence, growth, and biomass and productivity (Singh et al. 2015; Agathokleous 2017; Tiwari 2017). However, the mechanisms explaining its mode of action as a protectant against $\mathrm{O}_{3}$-induced toxicity vary among and within species, while the specific underpinning molecular/genetic mechanisms remain unclear (Paoletti et al. 2014; Agathokleous et al. 2015; Singh et al. 2015; Pandey et al. 2015, 2019; Jiang et al. 2018; Ashrafuzzaman et al. 
2018). It also remains unknown whether EDU can improve the biomass production of energy-crop willows cultivated with no pot-imposed root limitation under elevated $\mathrm{O}_{3}$.

Salicaceous species are widely distributed in Northeast Asia, including Hokkaido, the northernmost of the four main islands of Japan (Agathokleous et al. 2016b). Salix sachalinensis F. Schmid is a major, fast-growing willow species in willow-occurring environments, such as across the floodplain of Hokkaido's Ishikari River where it is a broad niche species (Niiyama 1987). That $S$. sachalinensis grows in highly humid environments suggests a high potential for increased $\mathrm{O}_{3}$ uptake due to relatively more open stomata, and $S$. sachalinensis saplings grown in pots were found susceptible to elevated $\mathrm{O}_{3}$ (Agathokleous et al. 2016b, 2018). To this end, we became interested in revealing whether $S$. sachalinensis trees grown in communities and with no root limitation due to pot effect (planted directly on the ground) would be adversely affected by elevated $\mathrm{O}_{3}$. We also hypothesized that EDU can decrease $\mathrm{O}_{3}$-induced negative effects, thus offering a perspective for applying EDU to enhance $S$. sachalinensis biomass production in an $\mathrm{O}_{3}$-polluted atmosphere. This research consisted of three parts (Table 1). Ozone effect on nutrients other than $\mathrm{C}$ and $\mathrm{N}$ remains poorly understood in open field-grown shrubs/trees, especially for different types of leaves (Shi et al. 2017; Agathokleous et al. 2018; Shang et al. 2018). Hence, in the first part, we carried out an assessment of elevated $\mathrm{O}_{3}$ effect on $\mathrm{S}$. sachalinensis in the first growing season to evaluate chemical status ( $\mathrm{Mg}, \mathrm{K}, \mathrm{Ca}, \mathrm{Mn}, \mathrm{Fe}, \mathrm{Ni}, \mathrm{Al}, \mathrm{Cr}, \mathrm{P}$ ) in top and fallen leaves and identify mechanisms of elemental regulation that can potentially explain $\mathrm{O}_{3}$ effects on plant physiology. In the second part, we evaluated whether EDU can protect against $\mathrm{O}_{3}$-induced phytotoxicity in the second growing season, i.e. after cuttings re-grew following the harvest of the shoots formed in the first growing season. In this part we also aimed at revealing underlying physiological mechanisms which could potentially explain the so far obscure mode of action of EDU in protecting willow against $\mathrm{O}_{3}$ (Agathokleous et al. 2018). In the third part, we became interested in investigating whether there are $\mathrm{O}_{3}$ and EDU carry-over effects in the third growing season, following the harvest of the EDU- and $\mathrm{O}_{3}$-treated shoots formed in the second growing season and cultivation of cuttings in ambient air conditions. Carry-over effects would indicate potential existence of 'memory' in the newly-developed shoots exposed to ambient air conditions in the third growing season, even after the removal of the EDUand $\mathrm{O}_{3}$-treated shoots formed in the second growing season. The results of this study provide a perspective to enhance biomass production of this important energy crop, especially considering that the cost of willow biomass is much higher than the cost of coal (Volk et al. 2006).

\section{Materials and methods}

\section{Experimental site}

The experiment was performed within the Sapporo Experimental Forest $\left(43^{\circ} 0^{\prime} \mathrm{N}, 141^{\circ} 2^{\prime}\right.$ E, $15 \mathrm{~m}$ a.s.l.) of the Field Science Center of Northern Biosphere (FSC), Hokkaido University, Sapporo, Japan, during the growing seasons of 2014, 2015, and 2016. The snow-free period commonly lasts from late April to mid-November. Meteorological information was recorded at a nearby station $\left(43^{\circ} 3.6^{\prime} \mathrm{N}\right.$ $141^{\circ} 19.7^{\prime}$ E) run and supervised by the Japan Meteorological Agency (http://www.jma.go.jp/jma/indexe.html). The averages ( \pm indicates standard deviation for meteorological data only) of the main parameters data were calculated for the months April-September of the three years. The values of the monthly average, daily minimum, and daily maximum air temperature were $(17.1 \pm 0.1)^{\circ} \mathrm{C},(13.4 \pm 0.2)^{\circ} \mathrm{C}$, and $(21.7 \pm 0.3)^{\circ} \mathrm{C}$, respectively. The average values of the

Table 1 A synopsis of the experiment

\begin{tabular}{|c|c|c|c|}
\hline Part & Year & Treatments & Response indicators \\
\hline \multirow[t]{2}{*}{1} & 2014 & Ambient or elevated ozone & $\begin{array}{l}\mathrm{SPAD}, \mathrm{LMA} \text {, and nutrients }(\mathrm{Mg}, \mathrm{K}, \mathrm{Ca}, \mathrm{Mn}, \mathrm{Fe}, \mathrm{Ni}, \mathrm{Al}, \mathrm{Cr}, \mathrm{P}) \text { in } \\
\text { top and fallen leaves }\end{array}$ \\
\hline & 2015 & $\begin{array}{l}\text { Soon after snowmelt, before treatments, all the main branches } \\
\text { but one developed in the previous year on each cutting were } \\
\text { harvested }\end{array}$ & Shoot growth and biomass production \\
\hline 2 & 2015 & $\begin{array}{l}\text { Ambient or elevated ozone and no-ethylenediurea or ethylen- } \\
\text { ediurea }\end{array}$ & $\begin{array}{l}\text { Plant physiology (FM/DM, LMA, gas exchange in } \\
\mathrm{O}_{3} \text {-asymptomatic leaves, photosynthetic pigments in both } \\
\mathrm{O}_{3} \text {-symptomatic and -asymptomatic leaves), growth, biomass } \\
\text { production, and foliage damage by insects }\end{array}$ \\
\hline 3 & 2016 & $\begin{array}{l}\text { None (carry-over assay) Note: all shoots were harvested, and } \\
\text { cuttings with their root system were transplanted into new } \\
\text { ambient sites for ratoon growth }\end{array}$ & $\begin{array}{l}\text { Physiology (SPAD, } N_{P P W}, \text { LMA, and } F_{v} / F_{m} \text { ), foliage damage } \\
\text { caused by insects and number of insects grazing foliage, plant } \\
\text { growth, and plant biomass }\end{array}$ \\
\hline
\end{tabular}

LMA stands for leaf mass per area and FM/DM for leaf fresh mass (FM) to dry mass (DM) ratio. NPPW indicates the estimated N content per leaf area, $F_{v} / F_{m}$ the maximum efficiency of PSII photochemistry, and SPAD the leaf greenness 
monthly total sunshine duration, relative humidity, and monthly precipitation were $194.7 \pm 9.4 \mathrm{~h}, 67.6 \% \pm 0.6 \%$, and $107.0 \pm 11.1 \mathrm{~mm}$, respectively. Finally, the wind speed was $3.69 \pm 0.19 \mathrm{~m} \mathrm{~s}^{-1}$.

\section{Plant material and cultivation within $\mathrm{O}_{3}$ FACE system}

Current-year cuttings of $S$. sachalinensis, originated from the river basin of Ebetsu city, were obtained from Hokkaido Horti-Tree Planting Center, Co. Ltd., and kept in a laboratory incubator $\left(0-4{ }^{\circ} \mathrm{C}\right)$ for one month to break the dormancy. On 13 May, 2014, cuttings were planted in containers filled with commercial soil, and left on the field for rooting and establishment (under partial shading for the first two weeks). The soil substrate was a mixture (1:1) of Kanuma (well-weathered pumice) and Akadama (wellweathered volcanic ash), originated from Kanuma town, Tochigi prefecture (DCM Homac CO., LTD., Sapporo, JP). The characteristics of the soil substrate used in this study have been previously described in detail (Agathokleous et al. 2016b, 2021a). While the plants were rain-fed over the course of the experiment, on 1, 2 and 3 June, 2014, the willow cuttings were well irrigated due to abnormally high ambient air temperatures (reaching $34-37^{\circ} \mathrm{C}$ ). On 12 June, 2014, 72 uniform rooted cuttings were transplanted directly on the ground of the FACE plots (12 per FACE plot, 6 per soil type). At this stage, the 72 saplings had on average $4.4 \pm 0.2$ branches/shoots ( \pm refers to standard error hereafter), $40.8 \pm 1.8$ leaves on all shoots, and $9.8 \pm 0.3$ leaves per shoot. The average shoot height was $12.6 \pm 0.2 \mathrm{~cm}$, while the average diameter at the base, middle, and upper part of the cutting was $19.4 \pm 0.2,18.5 \pm 0.2$ and $18.5 \pm 0.2 \mathrm{~mm}$, respectively (measured in $\mathrm{mm}$ with an electronic caliber; 2-decimal accuracy). The plant-to-plant distance was $50 \mathrm{~cm}$. In this mixed-species community grown in each plot, there were clusters of each species, i.e., plants of one species were not planted within clusters of other species. Species other than willow were grown in the same FACE plots for studies not related to this work (e.g., Agathokleous et al. 2016b, 2021a). In each plot, willow cuttings were planted in two soil types (3 cuttings per soil type), viz. brown forest soil (BF: Dystric Cambisols), which is native to the experimental field, and BF mixed (1:5 v/v) with immature volcanic ash plus pumice soil (VA-BF; Vitric Andosols). Further details of the experimental design, including the composition of the tree communities growing within the plots, and the soils can be found in supplementary materials of an earlier article (Agathokleous et al. 2021b).

On June 21, July 8, July 21, and August 25, 2014, the weeds in the plots were removed mechanically (by hand). Furthermore, on June 19, 2014, and May 7, 2015, plants were sprayed with insecticide due to high populations of insects grazing the foliage. The insecticide composition was etofenprox $0.020 \%$ and water and surfactant etc. $99.98 \%$ (Earth Garden T, Earth Corporation, Chiyoda-ku, Tokyo, Japan) in 2014 and clothianidin $0.0080 \%$, fenpropathrin $0.010 \%$, and water and surfactant etc. $99.982 \%$ (Benika-J spray, Sumitomo Chemical Garden Products Inc., Chuoku, Tokyo, Japan) in 2015. The insecticides were applied according to the manufacturer instructions. No other chemical or physical treatments were applied over the course of the experiments, except those described herein.

\section{EDU treatments}

EDU treatments were carried out in the second growing season (2015). After allocating 3 randomly-selected plants per soil type per plot to each EDU treatment (i.e. 6 plants per FACE plot per EDU treatment), plants were sprayed with water solution containing either 0 or $400 \mathrm{mg} \mathrm{EDU} \mathrm{L}^{-1}$ (no surfactant was included). An electric sprayer, which had two independent nozzles spraying at the same time, was used to spray both sides of leaf with fine mist based on Venturi effect. The EDU concentration tested was $400 \mathrm{mg} \mathrm{L}^{-1}$ because it can be considered the upper limit of EDU concentrations applied in research programs with sufficient protection against $\mathrm{O}_{3}$ phytotoxicity (Feng et al. 2010; Agathokleous 2017). Moreover, this concentration was found to offer sufficient protection against elevated $\mathrm{O}_{3}$ to willows grown from the same cutting lot (Agathokleous et al. 2016b). EDU was applied as a foliar spray in the present study because it protected only when it was sprayed to plants (not when applied as soil drench) in the earlier experiment with plants grown in pots for one growing season (Agathokleous et al. 2016b). No more EDU was needed when applied as foliar spray to current-year willow plants grown in pots for one growing season, compared to soil drench (commonly given as $200 \mathrm{~mL}$ per plant), while the amount was even 2.3 times smaller for foliar spray when the plants had a small leaf area (Agathokleous et al. 2016b). EDU (100\% a.i.) was prepared $30 \mathrm{~min}$ prior to each application by gently warming and continuous stirring on electric hotplates (Carnahan et al. 1978; Manning et al. 2011). The first EDU application took place on April 14, 2015, and repeated every $9 \mathrm{~d}$ on average, till early September, 2015; on rainy days EDU application was postponed to the next non-rainy day. Hence, EDU treatments were applied 17 times in total. EDU was applied every $9 \mathrm{~d}$ according to an abundant literature with successful results across various species, and because of its known persistence in the leaf apoplast (Paoletti et al. 2009; Agathokleous 2017).

\section{$\mathrm{O}_{3}$ treatments}

The FSC FACE system with tree communities was used. This system consisted of 6 independent plots located at 
different positions within the experimental forest; for details, see open-access information presented previously (Agathokleous et al. 2021b). Three plots were enriched with $\mathrm{O}_{3}$ and served as elevated $\mathrm{O}_{3}(\mathrm{EOZ})$ treatment plots, while the rest of the plots were not enriched with $\mathrm{O}_{3}$, thus representing the ambient $\mathrm{O}_{3}(\mathrm{AOZ})$ condition. The enrichment of the EOZ plots was active during the daytime (07:00-17:00, Japan Standard Time, JST). EOZ treatment was active from August 15 to October 26, 2014, and from April 24 to October 26, 2015; however, harvest took place on September 15, 2015, marking the end of the exposure to EOZ as only the main stem (cutting) was left. $\mathrm{O}_{3}$ mixing ratios were logged at an 1-min interval using a TUV-1100 device (Tokyo Industries Inc. Tokyo, Japan). The average 10-h (07:00-17:00 Japan Standard Time, JST) $\mathrm{O}_{3}$ levels of AOZ were $20.7 \pm 5.5$ and $34.7 \pm 7.6 \mathrm{nmol} \mathrm{mol}^{-1}$ in the growing seasons of 2014 and 2015, respectively. The average 10- $\mathrm{h} \mathrm{O}_{3}$ levels in the three EOZ plots were $65.7 \pm 9.8,61.7 \pm 11.9$, and $62.0 \pm 11.5 \mathrm{nmol} \mathrm{mol}^{-1}$ in 2014 and 71.5 $\pm 9.4,76.0 \pm 7.6$, and $69.3 \pm 10.5 \mathrm{nmol} \mathrm{mol}^{-1}$ in 2015 . Such elevated $\mathrm{O}_{3}$ concentrations occur in wide areas of Japan and other regions of northeast Asia (Kume et al. 2009; Akimoto et al. 2015; $\mathrm{Li}$ et al. 2021), while the annual mean surface $\mathrm{O}_{3}$ over Japan exhibits an increase of $\approx 2.7 \mathrm{nmol} \mathrm{mol}^{-1}$ per decade (Nagashima et al. 2017). Further details about the $\mathrm{O}_{3}$ exposures in the FACE system during 2014 and 2015 growing seasons have been described elsewhere (see supplementary materials of Agathokleous et al. (2021b)). The average 10-h ambient $\mathrm{O}_{3}$ level in the growing season of 2016 (carry-over experiment) was $32.3 \pm 5.7 \mathrm{nmol} \mathrm{mol}^{-1}$ (Agathokleous et al. 2021a, b).

\section{Treatments effect assessment}

Ozone effects on leaf traits, as a function of soil, at the end of the first growing season (2014)

Mature and shed leaves were collected from 4 individuals of S. sachalinensis (1 per leaf type per plant) per soil type per FACE plot on 25 September, 2014. Mature (not senescing) leaves were collected from the base of the shoot, whereas the shoot was gently shaken and fallen leaves were collected. Leaf greenness (soil plant analysis development; SPAD) value was recorded as the average of two measurements per leaf (SPAD-502 m, Konica-Minolta, Osaka, Japan), and their leaf area was calculated using image analysis software; SPAD value positively correlates with chlorophyll $a$ content in willow saplings of the same cutting source (Agathokleous et al. 2016a). Then, leaves were air-dried and their absolute dry mass was measured with an electronic, digital scale. Leaves were analyzed for main nutrients $(\mathrm{Mg}, \mathrm{K}, \mathrm{Ca}, \mathrm{Mn}$, $\mathrm{Fe}, \mathrm{Ni}, \mathrm{Al}, \mathrm{Cr}, \mathrm{P}$ ) after digestion; the effect of $\mathrm{O}_{3}$ on these nutrients remains poorly understood compared to foliar $\mathrm{N}$ and $\mathrm{C}$ which have been extensively studied and well understood. The 50-mg leaf tissues (one sample per leaf type per plant per soil type per FACE plot) were digested with hydrogen peroxide and nitric acid, and element concentration analyses were carried out with an Inductive Coupled Plasma Mass Spectrometer (ICP-MS, IRIS/IRIS Advantage ICAP, Thermo Fisher Scientific Inc., MA, USA).

Ozone effects on plant growth and biomass production, as a function of soil, in early spring of the second growing season (2015)

Soon after snowmelt (4 May, 2015), all the main branches developed in the previous year on each stem/cutting, but the most vigorous, were harvested by cutting them at their base where they were attached to the main stem/cutting. There were on average 2-3 branches per stem/cutting, and each main branch represents a shoot with its own complex network of organs (e.g. branches of various orders/levels, buds, leaves). The most vigorous of the main branches was maintained for new growth to be able to manage EDU treatments and perform the experimentation in the second growing season. The length of each harvested branch was measured with a measuring tape with an 1-mm accuracy, while the lateral branches on each main branch were counted by visual observation. The basal diameter of each main branch was measured in mm (2-decimal accuracy) using an electronic caliber. Two cross-wise measurements were recorded, and the average value was calculated. The leaves were separated from the main branches (all wood, i.e. any-order branches), and the two types of organs (leaves and stems) were airdried to constant mass in ovens. The average length of main shoots, number of lateral branches per main branch, dry mass of main branches, and diameter of main branches was calculated for each plant. Furthermore, the sum of dry masses of all main branches per plant was calculated as the total aboveground biomass.

EDU impact against $\mathrm{O}_{3}$ effects on plant physiology, growth, and biomass production, as a function of soil, in the second growing season (2015)

To calculate LMA and leaf fresh mass (FM) to dry mass (DM) ratio (hereafter FM/DM), two randomly-selected mature leaves (from the base of the branch) were collected from each tree on 12 September, 2015, and their area and fresh and dry masses were measured (after air-drying at $60{ }^{\circ} \mathrm{C}$ to constant mass). The leaves were scanned (Canon LIDE 40, Tokyo, Japan), and the projected area was estimated (software LAI-32 v. 0.377e, Dr. K. Yamamoto, Graduate School of Bioagricultural Sciences, Nagoya University, Japan) after scanning the leaves. 
Gas exchange measurements took place during morning hours (completed by noon) of days with 'clean' weather, from September 3-10, 2015, using LiCor instruments (LI6400, Li-Cor Inc., Lincoln, NE, USA) measuring synchronously. Mature $\mathrm{O}_{3}$-asymptomatic leaves were randomly selected and subjected to 20-min acclimation to the chamber prior to analyzing $\mathrm{A} / \mathrm{Ci}$ curve (the curve of net $\mathrm{CO}_{2}$ assimilation rate, $\mathrm{A}$, to intercellular $\mathrm{CO}_{2}$ concentration, $\mathrm{Ci}$ ). The measured leaves were collected and stored immediately in deep freeze to be used for photosynthetic pigments analysis. Gas exchange was measured in 1-3 plants per treatments combination (EDU and soil) per $\mathrm{O}_{3}$ FACE plot, and LiCor instruments were rotated across plants of different treatment combinations and over time. Stomatal conductance $\left(g_{s 380}\right)$, net photosynthetic rate $\left(A_{380}\right)$, and transpiration rate $\left(E_{380}\right)$ were assessed at ambient $\mathrm{CO}_{2}\left(380 \mu \mathrm{mol} \mathrm{mol}^{-1}\right)$. The leaf temperature was $25.5^{\circ} \mathrm{C}$, the relative air humidity was $55-65 \%$, the vapor pressure deficit (vpd) was 1.0, and the light saturated photosynthetic active photon flux density (PPFD) was $1500 \mu \mathrm{mol}$ quanta $\mathrm{m}^{-2} \mathrm{~s}^{-1}$. The A/Ci curve was established by changing the $\mathrm{CO}_{2}$ level (12 levels) in the leaf chamber fluorometer, while maintaining constant temperature, PPFD, and relative humidity using the LI-6400 AutoProgram. Then, by means of a C3 plant biochemical model (Farquhar et al. 1980; Long and Bernacchi 2003), maximum rate of electron transport rate $\left(J_{\max }\right)$, maximum rate of carboxylation $\left(V_{C \max }\right)$, and net photosynthetic rate at saturated $\mathrm{CO}_{2}$ of $1500 \mu \mathrm{mol} \mathrm{mol}{ }^{-1}\left(A_{\max }\right)$ were estimated.

Photosynthetic pigments were analyzed in both $\mathrm{O}_{3}$-asymptomatic and $\mathrm{O}_{3}$-symptomatic leaves. Ozoneasymptomatic mature leaves, which were collected after measured for gas exchange and stored in deep freeze, were used for pigment analyses. Regarding $\mathrm{O}_{3}$-symptomatic leaves, two randomly-collected mature leaves, with typical $\mathrm{O}_{3}$ visible foliar injury in EOZ, were also collected from each tree per treatments combination per FACE plot in early September, and stored in deep freeze until further analyses. Two circular leaf disks (one per leaf; diameter $=1 \mathrm{~cm}$ ) of standard area per plant were inserted in tubes containing $4 \mathrm{~mL}$ of DMSO and kept in an incubator $\left(65^{\circ} \mathrm{C}\right)$ for $4 \mathrm{~h}$, while shaking periodically (Shinano et al. 1996). Leaf extracts were assessed (GeneSpec III; Hitachi Genetic Systems; MiraiBio, Alameda, CA) instantaneously following incubation, and the absorbance was measured at 470, 543, 648, and $665 \mathrm{~nm}$. Carotenoids were estimated according to the method of (Lichtenthaler 1987), using the recordings obtained at 543 and $470 \mathrm{~nm}$. Chlorophyll $a$, chlorophyll $b$, and chlorophyll $a+b$ were analyzed according to the method of Barnes et al. (1992) using the recordings obtained at the optical densities of 648 and $665 \mathrm{~nm}$. The ratios of chlorophyll $a$ to chlorophyll $b$ and chlorophyll $a+b$ to carotenoids were also calculated as indices of physiological stress.
On September 11, 2015, the height (in $\mathrm{cm}$ ) of all the plants was measured with a measuring tape. The diameter of the shoot of each plant was also measured with a digital caliber (2-mm accuracy) as the average of two cross-wise measurements at the base of the shoot (old, lignified part).

The aboveground part of all plants was harvested on September 15, 2015; the initially planted cutting was left for regrowth in 2016. Harvested plants were separated into old shoot (developed in 2014; lignified), new shoot (developed in 2015; fresh/green), lateral branches, and leaves, and airdried at $60{ }^{\circ} \mathrm{C}$ to constant mass. The dry mass was measured with a digital balance with an accuracy of $1 \mathrm{mg}$. The total aboveground biomass was calculated as the sum of old shoot, new shoot, lateral branches, and foliage.

At harvest (before drying), all the leaves of each plant were placed next to each other with no overlapping, with the adaxial surface facing up, on a large white surface for contrast. The percentage of foliage (0-100\% of total foliage area) damaged by insect grazing (mainly Agelastica coerulea) was estimated for each plant through visual observation.

EDU and $\mathrm{O}_{3}$ carry-over effects following cutting re-growth in the third growing season (2016)

To evaluate potential carry-over effects of $\mathrm{O}_{3}$, soil, and EDU, the cuttings were transplanted from the FACE plots into three newly-created ambient plots scattered around the experimental forest after the snowmelt in 2016 (27 April). To excavate the root system with the cutting (left after the September, 2016, harvest), a circular area of soil surface, with a diameter of $20 \mathrm{~cm}$, was marked around the cutting and excavated at a depth of $40 \mathrm{~cm}$; the soil was gently removed from the root system. Rooted cuttings of each treatment combination $\left(\mathrm{O}_{3}\right.$, EDU, soil) were randomly allocated to the three ambient plots while having cuttings from all FACE plot replicates, for all treatment combinations, in each new plot. Willow cuttings naturally re-grow by developing new shoots (main branches) following the harvest of the previous shoots, thus producing new biomass without needing to cultivate new cuttings. The distance from cutting to cutting was $50 \mathrm{~cm}$, while a completely randomized experimental design was employed. The cuttings were irrigated immediately after transplantation, on May 19 and 21, and on August 12 due to high temperatures. No chemical treatments were applied over the course of the growing season.

Leaves morphological traits, chlorophyll (SPAD), and estimated $\mathrm{N}$ content per leaf area $\left(N_{P P W}\right)$ were evaluated on September 18, 2016. Five mature sun-lit leaves were randomly sampled from each plant (all plants were evaluated). The fresh weight (g) was measured immediately. The length $(\mathrm{cm})$ and width (cm, the widest point) of each leaf was measured with a ruler. The individual leaf area $\left(\mathrm{g} \mathrm{m}^{-1}\right.$; one-side projection) was estimated using the product of leaf width 
and leaf length as predictor in the predictive model reported by Agathokleous et al. (2016a). From each leaf (all 5 leaves, all plants), the average value of 2 measurements was taken for SPAD (SPAD-502 m, Konica-Minolta, Osaka, Japan) and $\mathrm{N}_{\mathrm{PPW}}$ (Agriexpert PPW-3000, Satake Corp., Hiroshima, Japan), which significantly correlates with measured $\mathrm{N}$ content in willows grown from the same cutting source (Agathokleous et al. 2016a). Leaves were air-dried to constant mass in an oven $\left(60^{\circ} \mathrm{C}\right)$. Fresh and dry mass of leaves was measured with an electronic balance with a 3-decimal accuracy.

Chlorophyll fluorescence was measured by a pulse amplitude modulation fluorometer (PAM, EM-FluorCam-800MF, Photon system inst., Drasov, Czech Republic) on September 26, 2016, from 08:30 to 12:00 (local time). One randomlyselected, sun-lit, mature leaf per plant was measured (all plants were evaluated). Each leaf was adapted in dark for 15 min by wrapping with aluminum foil before measurement. The minimum fluorescence $\left(F_{o}\right)$ was measured using a low measuring modulated light, which is sufficient to induce significant variable fluorescence. Maximum fluorescence $\left(F_{m}\right)$ was measured by applying a saturated light pulse. The light reaction centers were open during $F_{o}$ measurement and closed during $F_{m}$ measurements. The maximum efficiency of PSII photochemistry $\left(F_{v} / F_{m}\right)$ was estimated (Sperdouli et al. 2021).

The percentage of insect damage of the foliage was ranked for each shoot (all plants) on October 8, 2016, as described earlier in the text, and the number of individual adult beetles (A. coerulea) grazing each shoot was counted for all plants.

All plants were harvested on October 8, 2016, and their growth and biomass were measured. The length and basal diameter of each shoot were measured with a measuring tape $(\mathrm{cm}$; 1-decimal accuracy) and a digital caliper (mm; 2-decimal accuracy). The aboveground parts of all plants, which were developed in 2016 , were air-dried $\left(60^{\circ} \mathrm{C}\right)$ to constant mass in ovens. The aboveground dry mass of each plant was measured with an electronic balance (g; 1-decimal accuracy).

For some of the data obtained in 2016, some of the plant treatments could not be identified due to technical errors (e.g., missing or unreadable plant ID number). Hence, these data were considered missing values and excluded from the calculations and data analyses. However, there were sufficient statistical units for all the analyses.

\section{Data analyses}

The level of statistical significance was defined at $\alpha=0.05$. For datasets with more than one measurement per leaf and individual plant, data were averaged per leaf and plant. For statistical analyses, the average value of all measured individual plants in each soil type and FACE plot was used, thus giving three real replicates to serve as statistical units. The data of all response variables were subjected to Box-Cox power transformation, as described previously (Agathokleous et al. 2016c). SPAD, LMA, and leaf nutrient data obtained in the first growing season (2014) and growth and biomass data obtained in early spring of the second growing season (2015) were analyzed with a General Linear Model (GLM) with Type III Sums of Squares (SS) attributable to an effect, which is calculated as the SS for the effect controlling for any effects of lower or equal degree and orthogonal to any effects (if any) of higher order interaction that contain it. The method for recoding categorical predictors used was the 'overparameterized model' for representing categorical predictor variables. Ozone and Soil were fixed factors and Plot was random factor. Physiological, growth, and biomass production data obtained later in the second growing season (September, 2015) were subjected to the same GLM model, but with EDU as an additional factor. Ozone, EDU, and Soil were fixed factors and Plot was random factor. Regarding EDU and $\mathrm{O}_{3}$ carry-over effects following cutting re-growth in the third growing season (2016), Soil was excluded from the fixed factors to simplify the analysis because the previous statistical analyses of 2014 and 2015 data revealed no any important influence of soil on $\mathrm{O}_{3}$ and EDU effects (see section Results). Hence, the data of 2015 were subjected to the same GLM analysis; however, with $\mathrm{O}_{3}$ and EDU as fixed effect factors and FACE plot, soil, and ambient plot (created in 2016) as random effect factors. Since soil had no any important influence on $\mathrm{O}_{3}$ and EDU effects (see section Results), the data specific to each soil are also not presented for the data of the second growing season $\left(\mathrm{O}_{3} \times\right.$ EDU $\times$ Soil $)$ to facilitate interpretation and presentation of results. For all GLM tests, multiple comparisons among means for significant main effects with more than two levels (groups) were evaluated with Bonferroni test. For elements content in top and fallen leaves exhibiting significant main effect of $\mathrm{O}_{3}$, associations between elements were evaluated with multiple linear regression using all raw (untransformed) data. To evaluate the effect magnitude of significant EOZ and EDU400 effects, the Cohen's delta $(\delta)$ was computed as described by Agathokleous et al. (2016c), using raw (untransformed) data. The effect magnitude was categorized into neutral $(\delta=[0.00$, $0.50))$, small $(\delta=[0.50,1.50))$, moderate $(\delta=[1.50-3.00))$ or large $(\delta=3.00+)$ (Cohen 1988; Agathokleous et al. 2016a). Calculations and data processing as well as statistical analyses were executed within EXCEL 2010 (Microsoft, Redmond, CA, USA) and STATISTICA (v.10, StatSoft, Tulsa, OK, USA). The effect size was computed using an available Excel application (Agathokleous and Saitanis 2020). 


\section{Results}

\section{Ozone effects on plant physiology, as a function of soil, in the first growing season (2014)}

EOZ led to typical $\mathrm{O}_{3}$ foliar visible injury of varied intensity in selected leaves of various ages (Fig. 1).

Regarding randomly-selected young, top leaves, neither $\mathrm{O}_{3}$ nor soil was significant for SPAD (Fig. 2A) and LMA (Fig. 2B). Ozone was a significant main factor for $\mathrm{Mg}$ (Fig. 3A), Mn (Fig. 3B), Fe (Fig. 3C), Al (Fig. 3D), and Cr (Fig. 3E), but not for K (Fig. 4A), Ni (Fig. 4B), Ca (Fig. 4C), and $\mathrm{P}$ (Fig. 4D). In particular, EOZ led to 5.0, 1.4 and 1.8 times more $\mathrm{Mg}, \mathrm{Fe}$ and $\mathrm{Cr}$, respectively, and 1.5 and 1.5 times less $\mathrm{Mn}$ and $\mathrm{Al}$, compared to AOZ (Fig. 3). The effect

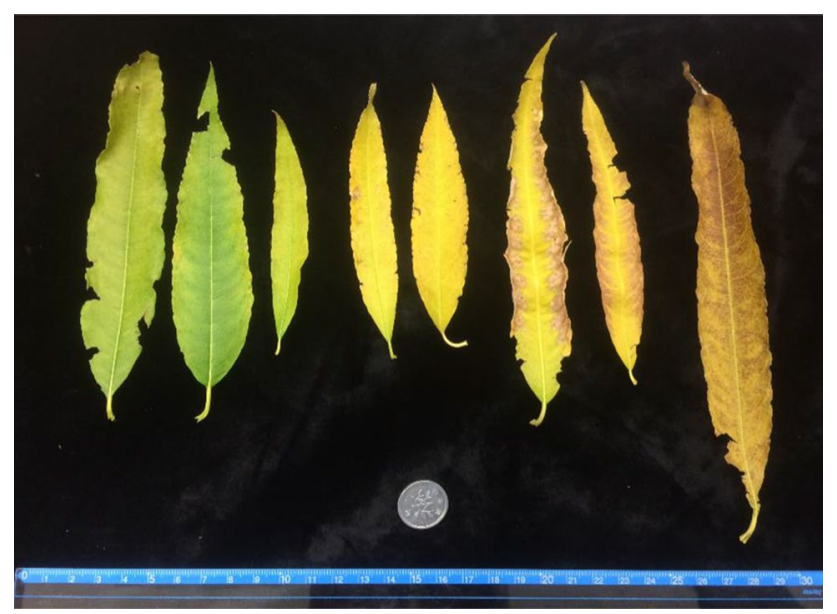

Fig. 1 Ozone-induced visible injury on selected leaves of willow $(S$. sachalinensis) shrubs. The picture presents various degrees of injury on leaves of different levels of maturity. The shrubs were grown from cuttings in plots enriched with elevated ozone levels, in a free-air ozone-concentration enrichment (FACE) system. This observation took place at the end of the first growing season (2014). No such injuries were observed in shrubs grown in the ambient ozone plots. Photo credit: Evgenios Agathokleous

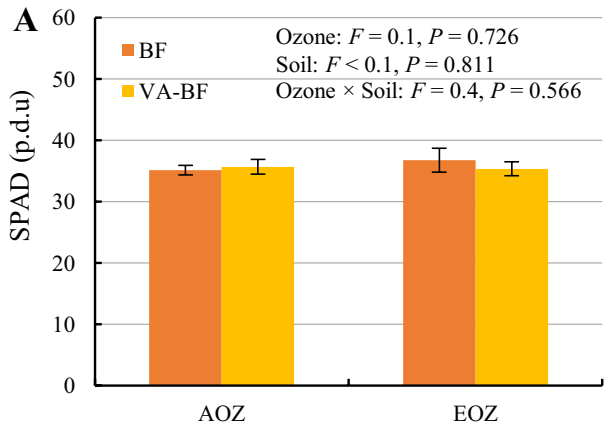

Fig. 2 Means $( \pm$ se, $n=3$ ) of leaf greenness (SPAD) and leaf mass per area (LMA) in leaves of willow ( $S$. sachalinensis) shrubs grown in brown forest (BF) or volcanic ash added to BF (VA-BF) soil and of $\mathrm{EOZ}$ was moderate for $\mathrm{Mn}(\delta=2.43$, CI $[2.39,2.45]), \mathrm{Fe}$ $(\delta=1.64, \mathrm{CI}[1.59,1.68]), \mathrm{Al}(\delta=1.97, \mathrm{CI}[1.95,1.98])$, and $\mathrm{Cr}(\delta=2.26$, CI $[2.24,2.27])$, and large for $\operatorname{Mg}(\delta=4.49$, CI $[2.78,4.74])$. Soil and $\mathrm{O}_{3} \times$ Soil interaction was nonsignificant for all the elements (Figs. 3, 4). Regarding the nutrients with a significant $\mathrm{O}_{3}$ effect, $\mathrm{Mg}$ was significantly anticorrelated with $\mathrm{Fe}(t=3.8, P<0.001)$ and $\mathrm{Al}(t=4.0$, $P<0.001)$ and correlated with $\mathrm{Cr}(t=5.2, P<0.001)$. Mn was correlated with only $\mathrm{Al}(t=4.5, P<0.001)$. Fe was anticorrelated with $\mathrm{Mg}(t=3.8, P<0.001)$ and correlated with $\mathrm{Cr}(t=3.3, P<0.01)$. Al was anticorrelated with $\mathrm{Mg}(t=4.0$, $P<0.001)$ and correlated with $\mathrm{Mn}(t=4.5, P<0.001) . \mathrm{Cr}$ was correlated with $\mathrm{Mg}(t=5.2, P<0.001)$ and $\mathrm{Fe}(t=3.3$, $P<0.01)$.

Regarding randomly-selected fallen leaves, $\mathrm{O}_{3}$ was a significant main factor for $\mathrm{Mg}$ (Fig. 5A), K (Fig. 5B), Mn (Fig. 5C), P (Fig. 5D), and $\mathrm{Al}$ (Fig. 5E) but not for Fe (Fig. 6A), Ca (Fig. 6B), Cr (Fig. 6C), and Ni (Fig. 6D). EOZ resulted in 1.3, 1.8, 2.4 and 1.5 times less $\mathrm{Mg}, \mathrm{Mn}, \mathrm{Al}$, and $\mathrm{P}$, respectively, and 1.2 times more $\mathrm{K}$, compared with $\mathrm{AOZ}$ (Fig. 5). The EOZ effect was small for $\mathrm{Mg}(\delta=1.41$, CI $[1.19,1.68])$ and $\mathrm{K}(\delta=1.12$, CI $[-0.83,3.82])$, moderate for $\mathrm{Mn}(\delta=1.97, \mathrm{CI}[1.87,2.03])$ and $\mathrm{P}(\delta=1.86$, CI [1.26, $2.24])$, and large for $\mathrm{Al}(\delta=4.29$, CI [4.25, 4.31]). Soil and Ozone $\times$ Soil main effects were significant only for $\mathrm{Fe}$ and Cr (Fig. 6). Plants in VA-BF had $33.0 \%$ and $37.9 \%$ more $\mathrm{Fe}$ and $\mathrm{Cr}$ in fallen leaves relative to plants in BF. For both $\mathrm{Fe}$ and $\mathrm{Cr}$, the only difference among means was between the means of $\mathrm{BF}$ and $\mathrm{VA}-\mathrm{BF}$ in $\mathrm{EOZ}$, i.e. plants grown in VA-BF had $78.5 \%$ and $65.7 \%$ more $\mathrm{Fe}$ and $\mathrm{Cr}$ in shed leaves, compared with plants grown in $\mathrm{BF}$, in EOZ. According to correlation analysis of nutrients with a significant $\mathrm{O}_{3}$ effect, $\mathrm{Mg}$ was anticorrelated with $\mathrm{K}(t=4.0, P<0.001)$ and $\mathrm{Cr}$ $(t=2.9, P<0.01)$ and correlated with $\mathrm{Fe}(t=2.9, P<0.01)$ and $\mathrm{Ni}(t=3.5, P<0.01)$. Mn was significantly correlated only with $\mathrm{Al}(t=4.0, P<0.01)$ and $\mathrm{Ca}(t=2.5, P<0.05)$. Al was anticorrelated with $\mathrm{Cr}(t=3.3, P<0.01)$ and correlated with $\mathrm{Mn}(t=4.0, P<0.001), \mathrm{Fe}(t=3.1, P<0.01)$, and $\mathrm{Ni}$

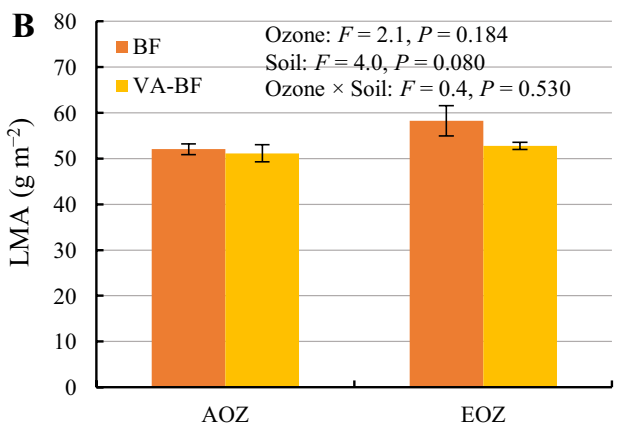

exposed to either ambient (AOZ) or elevated (EOZ) ozone. Sampling was performed at the end of the first growing season (2014). Data were analyzed with a General Linear Model (GLM) at $\alpha=0.05$ 
Fig. 3 Means $( \pm$ se, $n=3)$ of elements content (with significant effects ozone) in top leaves of willow (S. sachalinensis) shrubs grown in brown forest (BF) or volcanic ash added to $\mathrm{BF}$ (VA-BF) soil and exposed to either ambient (AOZ) or elevated (EOZ) ozone. Sampling was performed at the end of the first growing season (2014). Data were analyzed with a General Linear Model (GLM) at $\alpha=0.05$

Fig. 4 Means $( \pm$ se, $n=3)$ of elements content (with nonsignificant effects of ozone) in top leaves of willow $(S$. sachalinensis) shrubs grown in brown forest (BF) or volcanic ash added to BF (VA-BF) soil and exposed to either ambient (AOZ) or elevated (EOZ) ozone. Sampling was performed at the end of the first growing season (2014). Data were analyzed with a General Linear Model (GLM) at $\alpha=0.05$
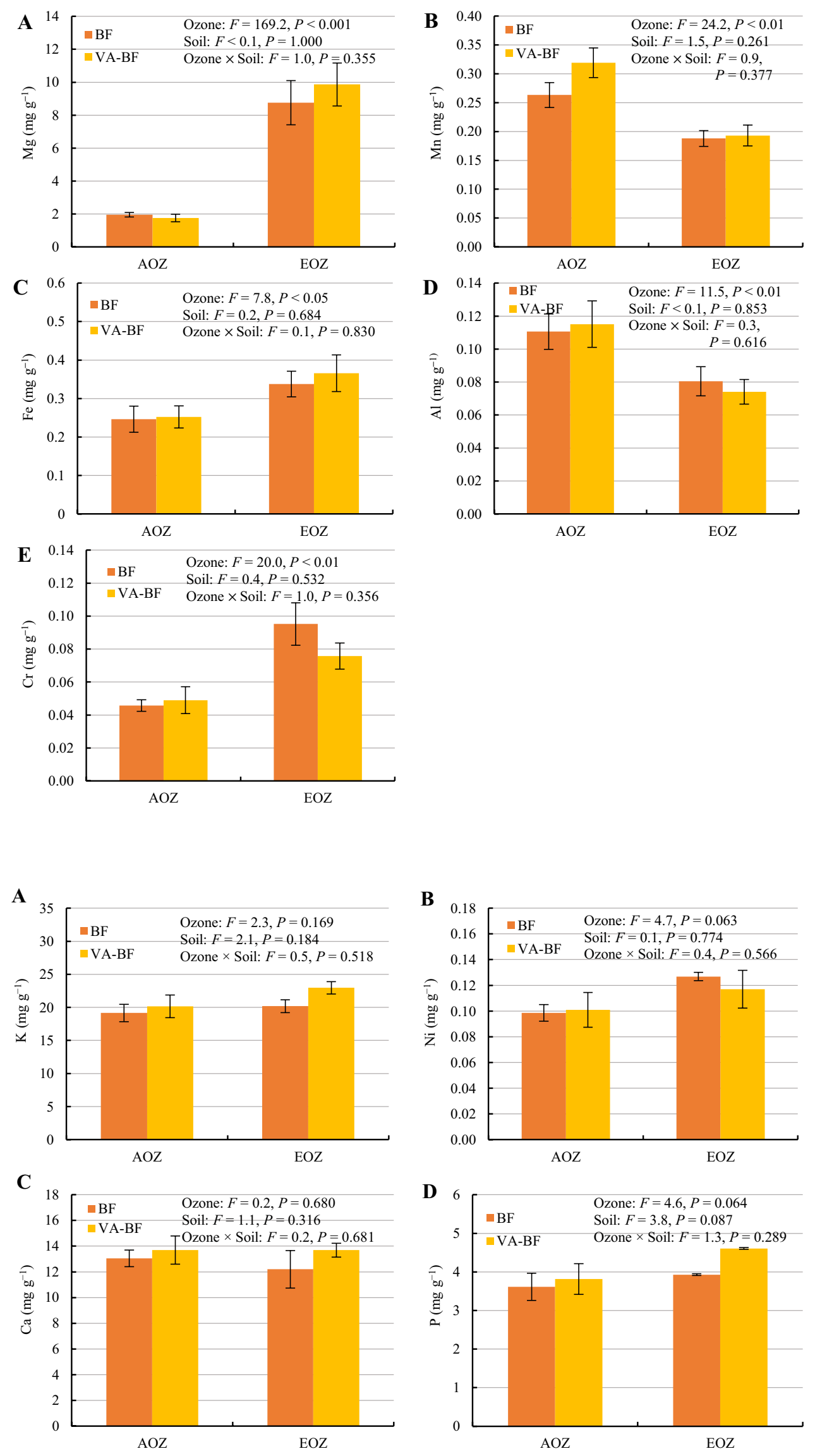
Fig. 5 Means $( \pm$ se, $n=3)$ of elements content (with significant effects of ozone) in fallen leaves of willow ( $S$. sachalinensis) shrubs grown in brown forest (BF) or volcanic ash added to BF (VA-BF) soil and exposed to either ambient (AOZ) or elevated (EOZ) ozone. Sampling was performed at the end of the first growing season (2014). Data were analyzed with a General Linear Model (GLM) at $\alpha=0.05$

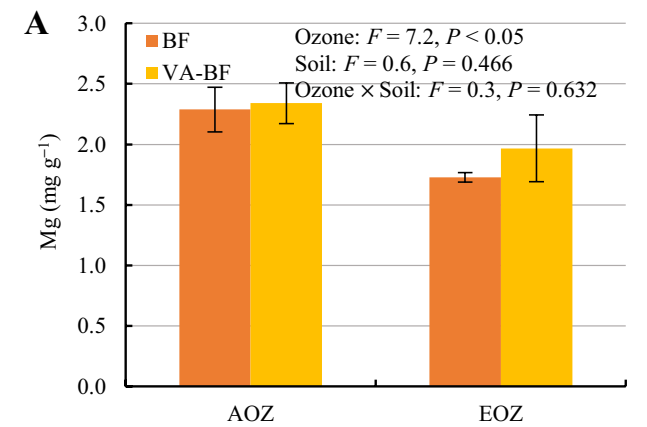

$$
\text { C }
$$
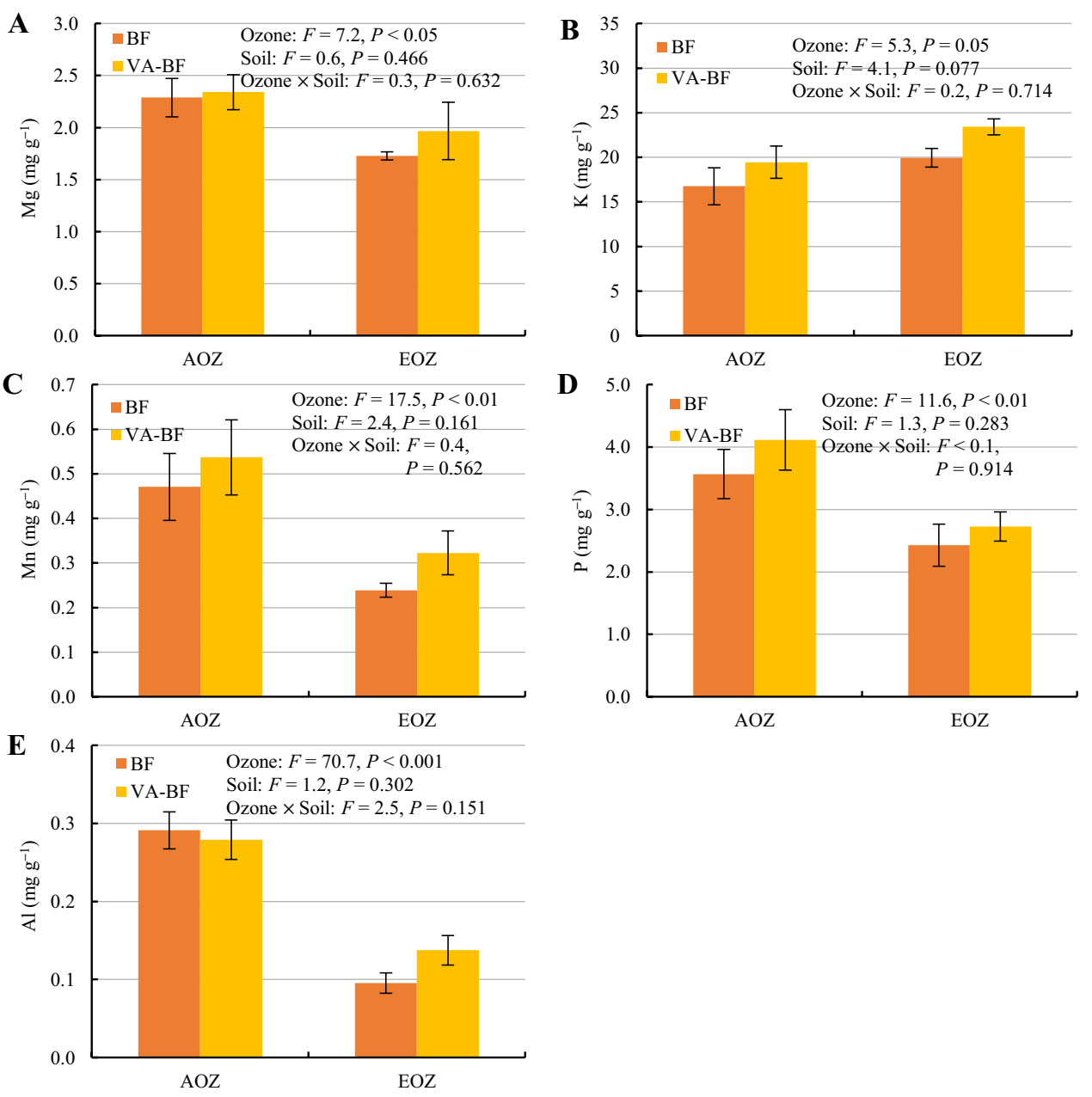

Fig. 6 Means $( \pm$ se, $n=3)$ of elements content (with nonsignificant effects of ozone) in fallen leaves of willow ( $S$. sachalinensis) shrubs grown in brown forest (BF) or volcanic ash added to BF (VA-BF) soil and exposed to either ambient (AOZ) or elevated (EOZ) ozone. Sampling was performed at the end of the first growing season (2014). Data were analyzed with a General Linear Model (GLM) at $\alpha=0.05$. For elements exhibiting a significant Ozone $\times$ Soil interaction, different letters above means indicate statistically significant differences between means based on Bonferroni post-hoc test $(\alpha=0.05)$
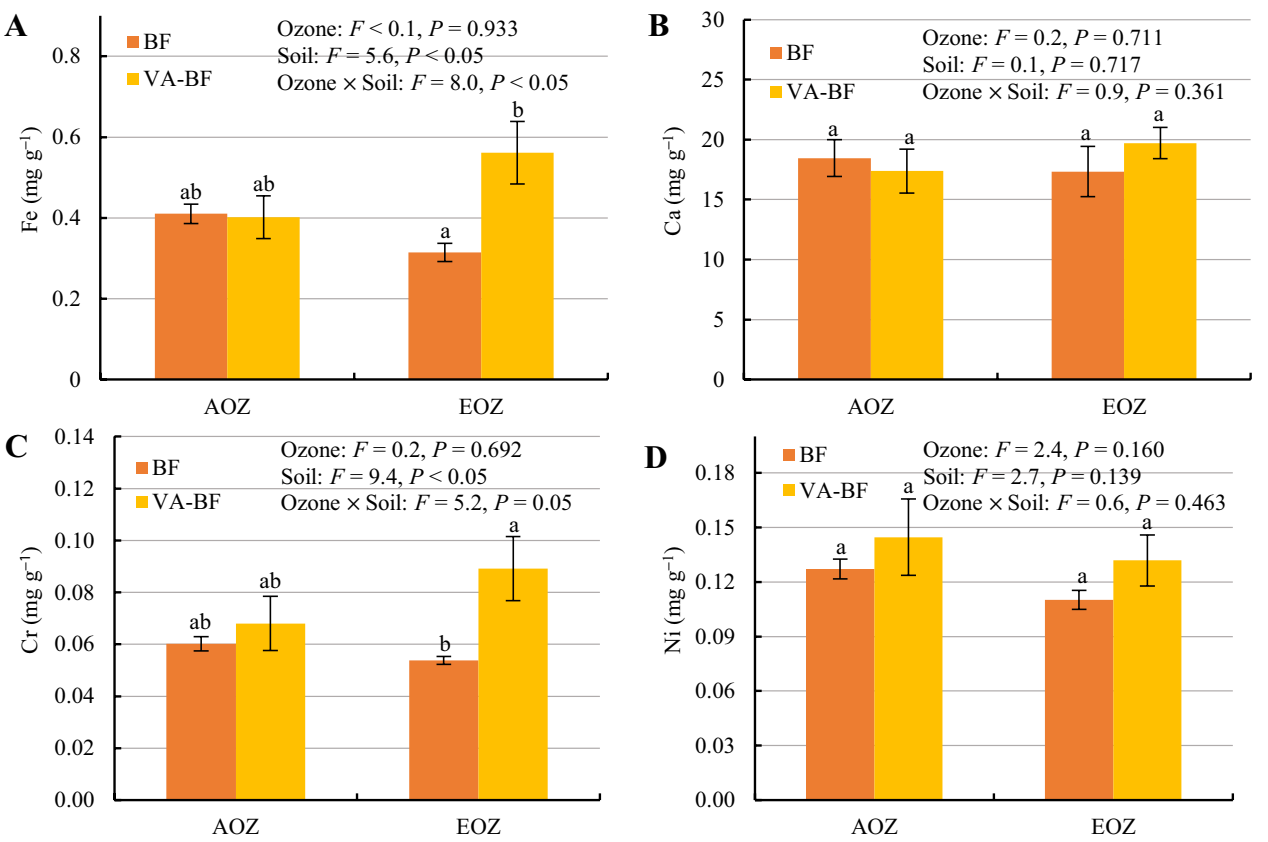
$(t=2.9, P<0.01)$. The only significant association of $\mathrm{K}$ was the anticorrelation with $\mathrm{Mg}(t=4.0, P<0.001)$. P was correlated with $\mathrm{Ni}(t=3.4, P<0.01)$ and anticorrelated with $\mathrm{Ca}$ $(t=2.2, P<0.05)$ and $\mathrm{Cr}(t=2.1, P<0.05)$.

\section{Ozone effects on plant growth and biomass production, as a function of soil, in early spring of the second growing season (2015)}

Ozone was a significant main factor for only total harvested aboveground biomass (Fig. 7D), where plants exposed to EOZ had $30.1 \%$ greater mean value than plants exposed to AOZ, an effect that was small in magnitude $(\delta=0.81$, CI $[-1.75,3.44])$. Ozone did not have a significant effect on traits at the level of average main branch, viz. length (Fig. 7A), dry mass (Fig. 7B), basal diameter (Fig. 7C), and number of lateral branches (Fig. 7E). Soil was a significant main factor for only total harvested aboveground biomass (Fig. 7D). In particular, plants grown in BF soil had $49.4 \%$ higher total harvested aboveground biomass than plants grown in VA-BF soil. Ozone $\times$ Soil interaction was significant for the average length, diameter, and dry mass of main branches. However, according to the 'strict' Bonferroni comparisons, there were no significant differences among means for average length and diameter of main branches. Regarding the average dry mass of main branches, the only significant difference among means was between plants grown in $\mathrm{BF}$ soil (83.1\% higher) and plants grown in VA-BF soil in AOZ.

\section{EDU impact against $\mathrm{O}_{3}$ effects on plant physiology, growth, and biomass production, as a function of soil, in the second growing season (2015)}

Regarding FM/DM (Fig. 8A) and LMA (Fig. 8B), the only significant factors were EDU and $\mathrm{O}_{3} \times$ EDU interaction. Plants treated with EDU400 had $7.7 \%$ higher mean value of FM/DM (small effect; $\delta=1.11$, CI [1.02, 1.19]) and $10.0 \%$ lower mean value of LMA (small effect; $\delta=0.99$, CI $[-2.34,5.48])$ compared with plants treated with EDU0 $\left(\mathrm{O}_{3}\right.$ and soil treatments pooled $)$. An examination of the $\mathrm{O}_{3} \times$ EDU interaction revealed that the only significant difference among means was between EDU0 and EDU400 within EOZ, for both FM/DM and LMA. In particular, leaves treated with EDU400 had $16.9 \%$ greater FM/DM
Fig. 7 Means $( \pm \mathrm{se}, n=3)$ of plant growth and biomass production of willow $(S$. sachalinensis) shrubs grown in brown forest (BF) or volcanic ash added to BF (VA-BF) soil and exposed to either ambient (AOZ) or elevated (EOZ) ozone. Sampling was performed after snowmelt, in early spring of the second growing season (2015). Data were analyzed with a General Linear Model (GLM) at $\alpha=0.05$. For traits exhibiting a significant Ozone $\times$ Soil interaction, different letters above means indicate statistically significant differences between means based on Bonferroni post-hoc test $(\alpha=0.05)$
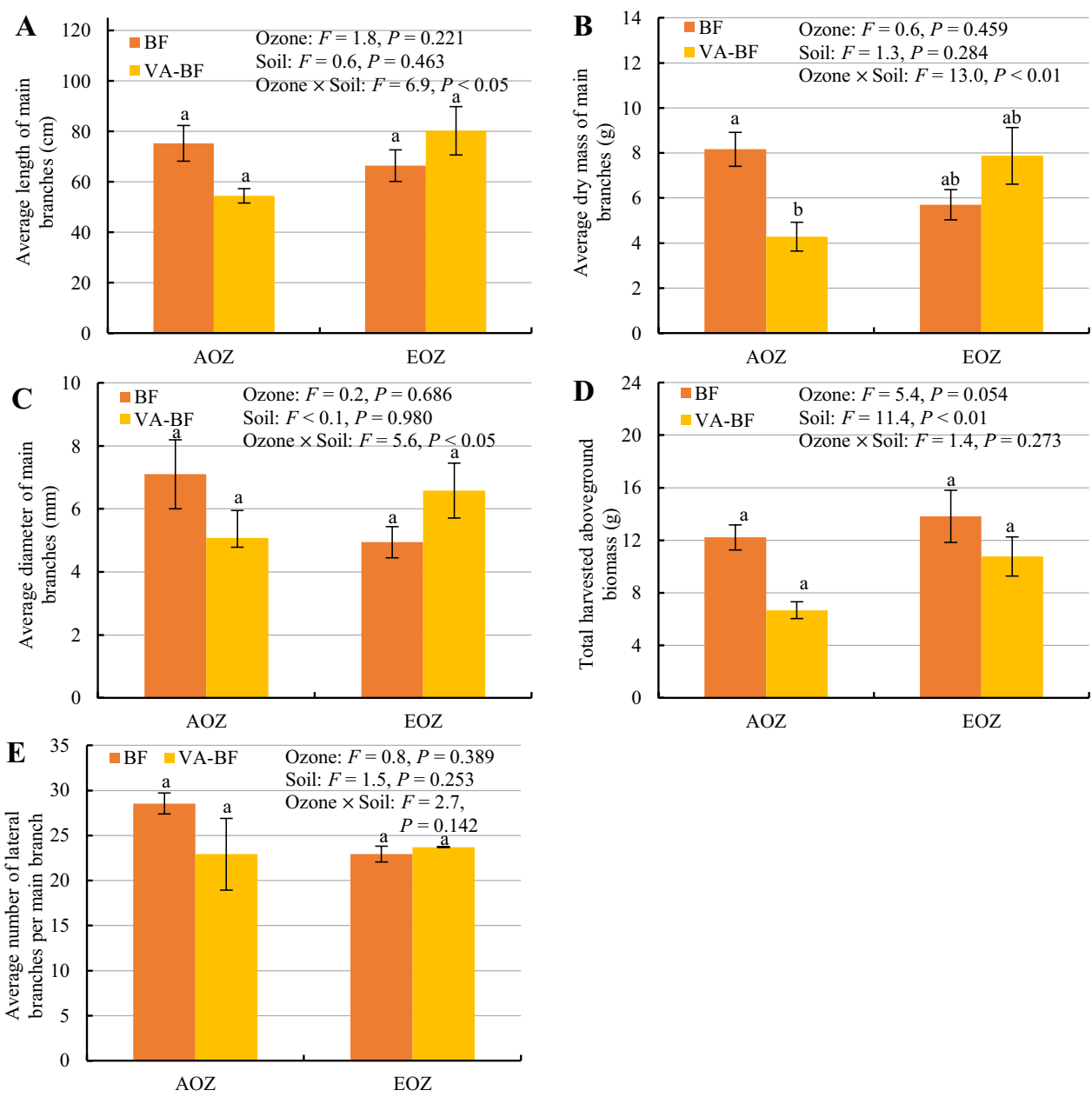


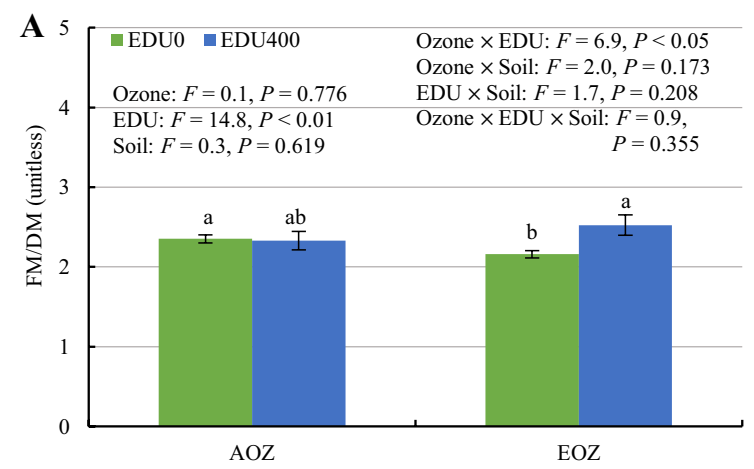

Fig. 8 Means $( \pm$ se, $n=6)$ of fresh mass (FM) to dry mass (DM) ratio (FM/DM) and leaf mass per area (LMA) of mature leaves of willow (S. sachalinensis) shrubs grown in brown forest (BF) or volcanic ash added to BF (VA-BF) soil, treated with 0 (EDU0) or 400 (EDU400) $\mathrm{mg} \mathrm{EDU} \mathrm{L}^{-1}$ every $9 \mathrm{~d}$, and exposed to either ambient (AOZ) or elevated (EOZ) ozone. Sampling was performed in early September of the second growing season (2015). Data were analyzed

value (moderate effect; $\delta=2.53$, CI $[2.41,2.63]$ ) and $18.6 \%$ smaller LMA value (moderate effect; $\delta=1.81$, CI $[-1.87,8.13])$, compared with leaves treated with EDU0, in EOZ (Fig. 8).

Treatments effects on gas exchange parameters were minimal in $\mathrm{O}_{3}$-asymptomatic leaves (Fig. 9). Ozone was a significant factor for only $A_{\max }$, for which a $16.1 \%$ lower mean was observed in EOZ-exposed plants, relatively to AOZexposed plants (Fig. 9F). The effect of EOZ on $A_{\max }$ was small $(\delta=0.81, \mathrm{CI}[-1.49,4.46])$. EDU had a significant main effect on only $A_{380}$ (Fig. 9A) and $E_{380}$ (Fig. 9E), which were increased $(18.4 \%)$ and decreased $(20.8 \%)$ by EDU400, compared to EDU0 (Fig. 9), effects that were small $\left(A_{380}\right.$ : $\delta=0.82$, CI $[-1.11,3.09] ; E_{380}: \delta=0.68$, CI $\left.[0.07,1.40]\right)$. Soil had a significant main effect on $g_{s 380}$ (Fig. 9C) and $E_{380}$ (Fig. 9E). Plants grown in $\mathrm{BF}\left(g_{s 380}:\right.$ mean $=0.53 \pm 0.025$ mol m${ }^{-2} \mathrm{~s}^{-1} ; E_{380}$ : mean $=0.46 \pm 0.029 \mathrm{mmol} \mathrm{m}^{-2} \mathrm{~s}^{-1}$ ) had $16.4 \%$ and $41.8 \%$ higher $g_{s 380}$ and $E_{380}$ than plants grown in VA-BF $\left(g_{s 380}\right.$ : mean $=5.2 \pm 0.23 \mathrm{~mol} \mathrm{~m}^{-2} \mathrm{~s}^{-1} ; E_{380}$ : mean $=$ $\left.3.7 \pm 0.33 \mathrm{mmol} \mathrm{m}^{-2} \mathrm{~s}^{-1}\right)$. The only significant interaction was that of $\mathrm{O}_{3} \times \mathrm{EDU}$ for $A_{\max }$ (Fig. 9F), which occurred due to $33.2 \%, 36.4 \%$, and $34.3 \%$ lower $A_{\max }$ in EDU0-EOZ plants than in plants of EDU400-EOZ $(\delta=1.45$, CI [ -1.47 , 6.47]; small effect), EDU0-AOZ ( $\delta=1.40, \mathrm{CI}[-2.81,6.43]$; small effect), and EDU400-AOZ ( $\delta=1.57$, CI $[-0.78,6.59]$; moderate effect), respectively.

Apart from $\mathrm{O}_{3}$, no other factor or factor interactions were significant for photosynthetic pigment traits in $\mathrm{O}_{3}$-asymptomatic leaves (Fig. 10). EOZ significantly decreased chlorophyll $a$ (23.0\%; Fig. 10A), chlorophyll $b$ (23.9\%; Fig. 10C), chlorophyll $a+b$ (23.3\%; Fig. 10E), and chlorophyll to carotenoid ratio $(12.1 \%$; Fig. $10 \mathrm{~F})$, compared to AOZ, effects that were small $(\delta=0.89$, CI [ -3.60 , $4.00])$, small $(\delta=0.97$, CI $[-0.58,1.94])$, small $(\delta=0.89$,

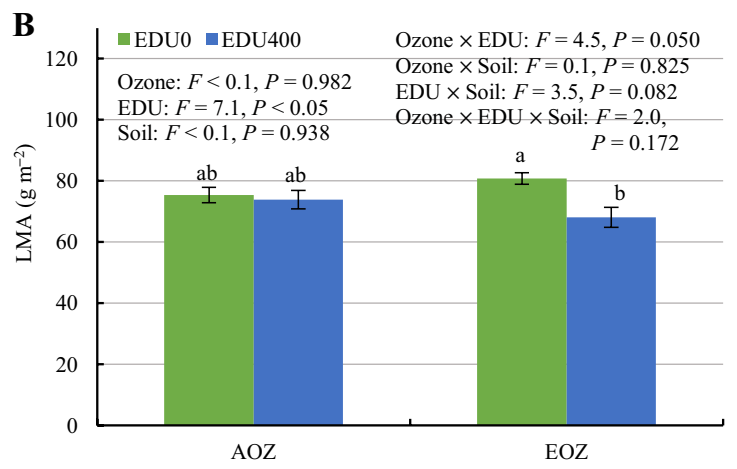

with a General Linear Model (GLM) at $\alpha=0.05$. For traits exhibiting a significant Ozone $\times$ EDU interaction, different letters above means indicate statistically significant differences between means based on Bonferroni post-hoc test $(\alpha=0.05)$. Since soil had no any important influence on $\mathrm{O}_{3}$ and EDU effects, the data specific to each soil are not presented for the data of the second growing season to facilitate interpretation and presentation of results

CI $[-5.02,5.25])$, and small $(\delta=0.84$, CI $[-0.07,2.04])$, respectively.

Ozone had a significant main effect on all photosynthetic pigment traits, except chlorophyll $a$ to $b$ ratio (Fig. 11D), in $\mathrm{O}_{3}$-symptomatic leaves. Specifically, EOZ inhibited chlorophyll $a$ (Fig. 11A), chlorophyll $b$ (Fig. 11C), chlorophyll $a+b$ (Fig. 11E), carotenoid (Fig. 11B), and chlorophyll to carotenoid ratio (Fig. $11 \mathrm{~F}$ ) by $54.0 \%, 47.1 \%$, $52.0 \%, 23.7 \%$, and $26.4 \%$, respectively, compared to AOZ. The effect of EOZ on chlorophyll $a$, chlorophyll $b$, chlorophyll $a+b$, carotenoid, and chlorophyll to carotenoid ratio was moderate $(\delta=2.03$, CI $[0.51,5.54])$, moderate $(\delta=2.15$, CI $[1.44,3.21])$, moderate $(\delta=2.13$, CI [-0.02, $6.57])$, small close to moderate $(\delta=1.48, \mathrm{CI}[0.79,2.17])$, and small $(\delta=1.33$, CI $[0.90,2.12])$, respectively. EDU had a significant main effect on chlorophyll $a$ (Fig. 11A), chlorophyll $a+b$ (Fig. 11E), and chlorophyll $a$ to $b$ ratio (Fig. 11D), which were 22.6\%, 20.0\%, and $12.4 \%$ higher in EDU400-treated plants, compared to EDU0-treated plants, respectively. The EDU400 effect on chlorophyll $a$ $(\delta=0.70$, CI $[-1.88,5.34])$, chlorophyll $a+b(\delta=0.65$, CI $[-2.82,6.83])$, and chlorophyll $a$ to $b$ ratio $(\delta=0.98$, CI $[0.84,1.16])$ was small. Ozone $\times$ EDU interaction was significant for all pigment traits except carotenoid and chlorophyll $a$ to $b$ ratio (Fig. 11D). For chlorophyll $a$ (Fig. 11A) and chlorophyll $a+b$ (Fig. 11E), the means of EDU0 $\times$ EOZ group were 1.6 and 1.6, 2.0 and 1.9, and 2.1 and 2.0 times smaller than the means of EDU $400 \times \mathrm{EOZ}$, EDU $0 \times \mathrm{AOZ}$, and EDU $400 \times \mathrm{AOZ}$, respectively, effects that were moderate, large, and large, respectively. The mean of EDU $400 \times \mathrm{EOZ}$ did not significantly differ from the means of EDU0 $\times \mathrm{AOZ}$ and EDU $400 \times \mathrm{AOZ}$ for both chlorophyll $a$ and chlorophyll $a+b$. Regarding chlorophyll $b$ (Fig. 11C) and chlorophyll to carotenoid ratio (Fig. 11F), 

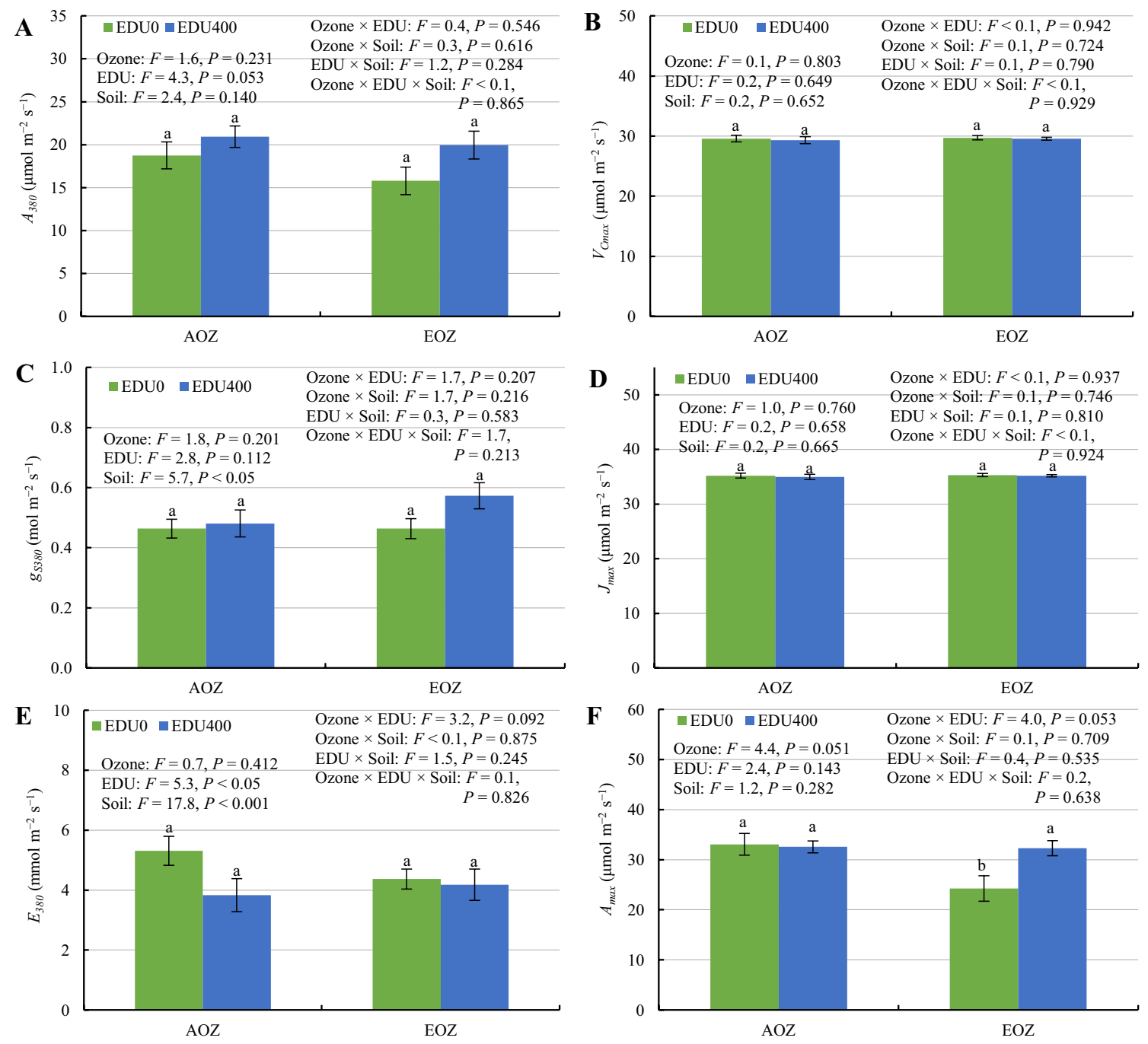

Fig. 9 Means $( \pm$ se, $n=6)$ of gas exchange parameters of mature $\mathrm{O}_{3}$-asymptomatic leaves of willow ( $\mathrm{S}$. sachalinensis) shrubs grown in brown forest (BF) or volcanic ash added to BF (VA-BF) soil, treated with 0 (EDU0) or 400 (EDU400) $\mathrm{mg} \mathrm{EDU} \mathrm{L}^{-1}$ every $9 \mathrm{~d}$, and exposed to either ambient (AOZ) or elevated (EOZ) ozone. The parameters were net photosynthetic rate $\left(A_{380}\right)$, stomatal conductance $\left(g_{S 380}\right)$, transpiration rate $\left(E_{380}\right)$, maximum rate of electron transport rate $\left(J_{\max }\right)$, maximum rate of carboxylation $\left(V c_{\max }\right)$, and net photo-

the only significant differences in the multiple comparisons were between EDU $0 \times$ EOZ group and EDU $0 \times \mathrm{AOZ}$ (1.8 and 1.5 times higher) and EDU400 $\times$ AOZ (1.8 and 1.4 times higher). The two pairs of means displayed a difference of large magnitude for chlorophyll $b$ and of moderate magnitude for chlorophyll to carotenoid ratio. Soil and interactions other than $\mathrm{O}_{3} \times$ EDU were non-significant for all the traits (Fig. 11).

Apart from a significant effect of $\mathrm{O}_{3}$ on plant height, there was no other significant main effect of single factors or interactions on plant height (Fig. 12A) and shoot basal diameter (Fig. 12B) at the end of the second growing season. synthetic rate at saturated $\mathrm{CO}_{2}$ of $1500 \mu \mathrm{mol} \mathrm{mol} \mathrm{m}^{-1}\left(A_{\max }\right)$. Measurements were performed in early September of the second growing season (2015). Data were analyzed with a General Linear Model (GLM) at $\alpha=0.05$. For traits exhibiting a significant Ozone $\times$ EDU interaction (only $A_{\max }$ ), different letters above means indicate statistically significant differences between means based on Bonferroni post-hoc test $(\alpha=0.05)$

EOZ-exposed plants were $16.6 \%$ taller than AOZ-exposed plants, an effect that was small $(\delta=0.99$, CI $[-15.34$, 28.25]).

Regarding biomass production, $\mathrm{O}_{3}$ main effect was significant only for old shoot dry mass (Fig. 13A) and total aboveground dry mass (Fig. 13D). Specifically, EOZ-exposed plants had $25.0 \%$ greater old shoot dry mass $(\delta=1.03$, CI $[-14.79,14.03])$ and $14.3 \%$ greater total aboveground dry mass ( $\delta=0.73$, CI $[-29.41,22.76])$, effects that were small in magnitude. EDU main effect was significant only for new shoot dry mass (Fig. 13C) and total aboveground dry mass (Fig. 13D), which were 
A
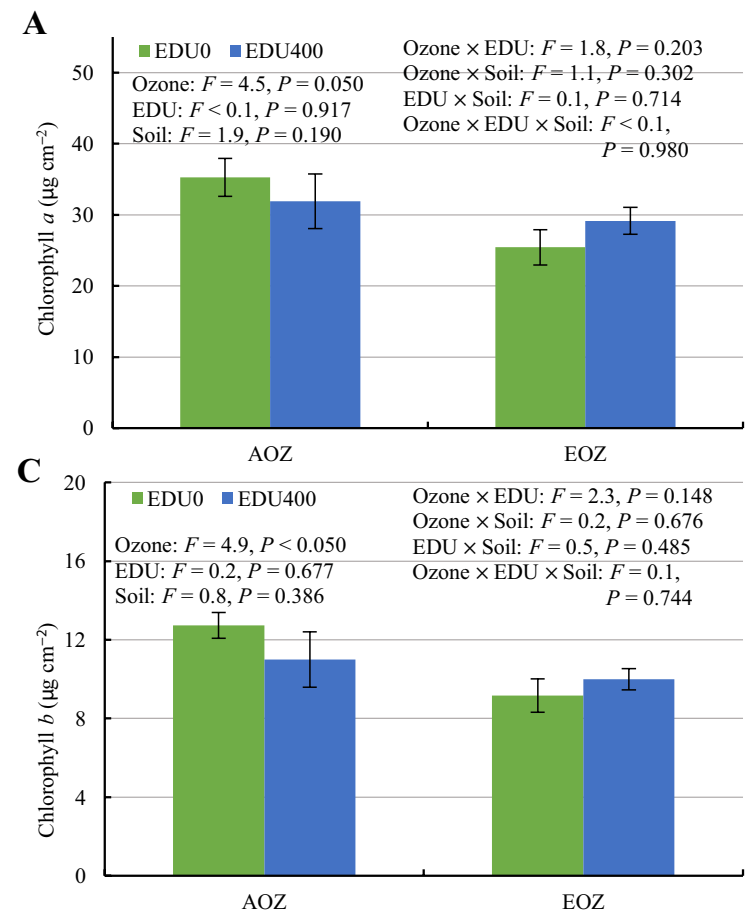

E

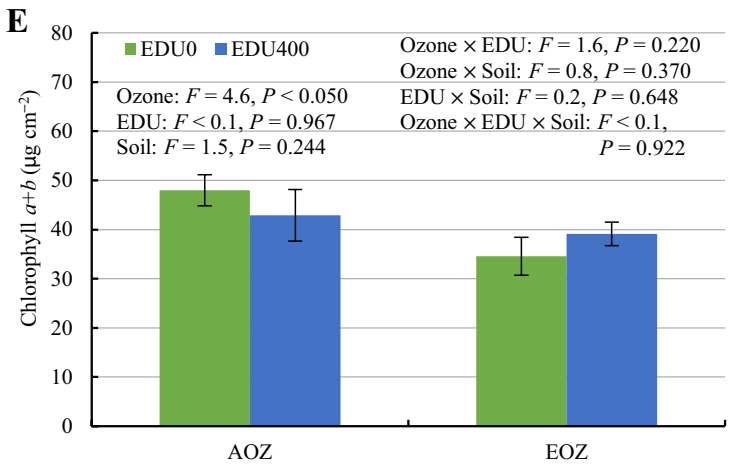

Fig. 10 Means $( \pm \mathrm{se}, n=6)$ of photosynthetic pigments of mature $\mathrm{O}_{3}$-asymptomatic leaves of willow ( $\mathrm{S}$. sachalinensis) shrubs grown in brown forest (BF) or volcanic ash added to BF (VA-BF) soil, treated with 0 (EDU0) or 400 (EDU400) mg EDU L ${ }^{-1}$ every $9 \mathrm{~d}$, and

28.6 and $13.9 \%$ greater in EDU400-treated plants than in EDU0-treated plants. The effect of EDU400 on new shoot dry mass $(\delta=1.22$, CI $[-4.60,5.51])$ and total aboveground dry mass $(\delta=0.71$, CI $[-30.03,22.16])$ was small. Soil was a significant main factor for new shoot dry mass only (Fig. 13C), with an $18.3 \%$ higher mean for plants grown in VA-BF $(49.4 \pm 2.4 \mathrm{~g})$, relative to plants grown in $\mathrm{BF}(41.8 \pm 3.3 \mathrm{~g})$. Ozone $\times \mathrm{EDU}$ interaction was significant for lateral branches dry mass (Fig. 13E), foliage dry mass (Fig. 13B), and total aboveground dry mass (Fig. 13D). However, there was no significant difference among means of lateral branches dry mass with the strict Bonferroni test. Regarding foliage dry mass, the only significant difference observed was a $36.1 \%$ higher mean of EDU400-treated plants compared to EDU0-treated
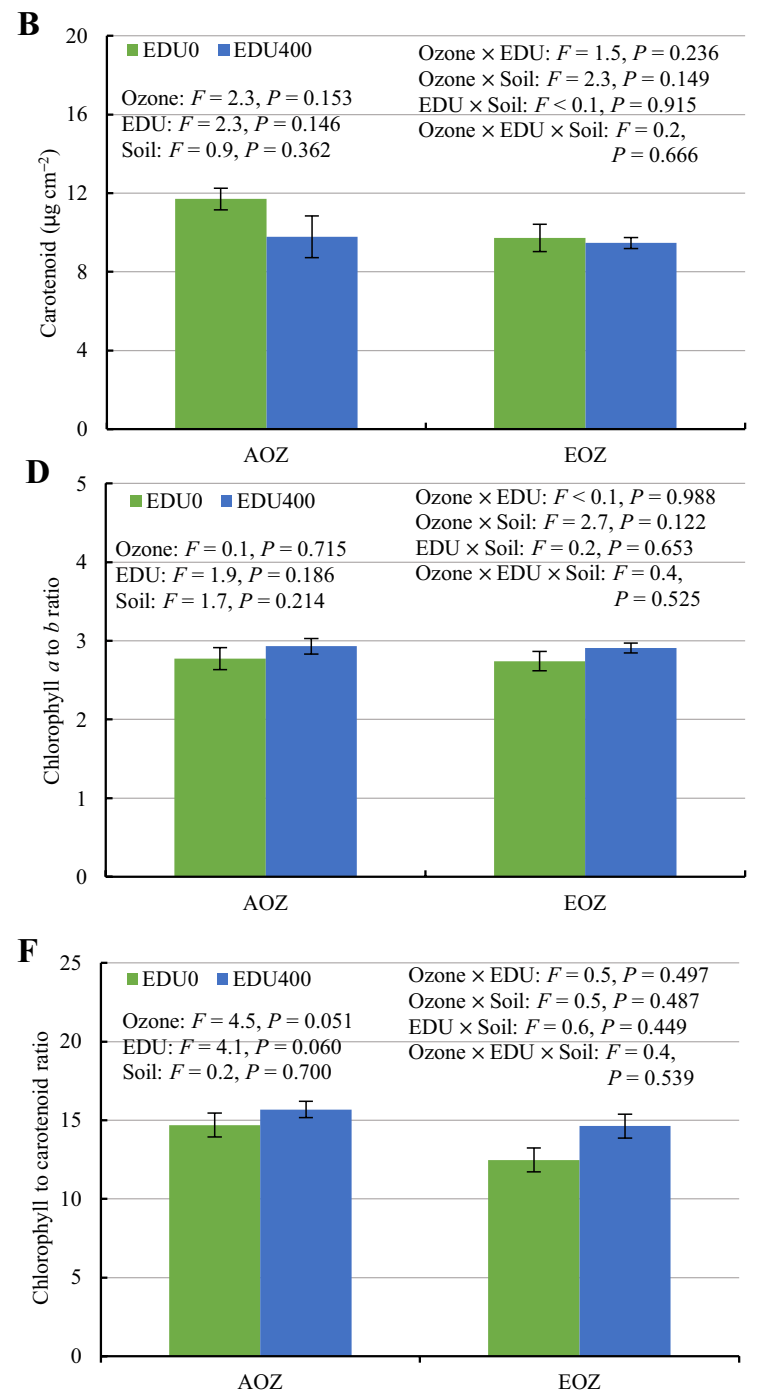

exposed to either ambient (AOZ) or elevated (EOZ) ozone. Sampling was performed after gas exchange measurements in early September of the second growing season (2015). Data were analyzed with a General Linear Model (GLM) at $\alpha=0.05$

plants in EOZ, an effect that was moderate (Fig. 13B). Regarding total aboveground dry mass (Fig. 13D), the mean of EDU $400 \times \mathrm{EOZ}$ group was $29.9 \%, 27.9 \%$, and $30.4 \%$ greater than the means of EDU $0 \times \mathrm{EOZ}$ (moderate effect), EDU $0 \times \mathrm{AOZ}$ (small near moderate effect), and EDU400 $\times$ AOZ (moderate effect) groups, respectively. Ozone $\times$ Soil interaction was significant for lateral branches dry mass (Fig. 13E); however, there was no significant difference among means with the strict Bonferroni. EDU $\times$ Soil interaction was a non-significant factor for all the traits. Ozone $\times$ EDU $\times$ Soil interaction was significant for new shoot dry mass (Fig. 13C), lateral branches dry mass (Fig. 13E), and total aboveground dry mass (Fig. 13D). However, there was no significant difference among means for lateral branches dry mass with the strict 

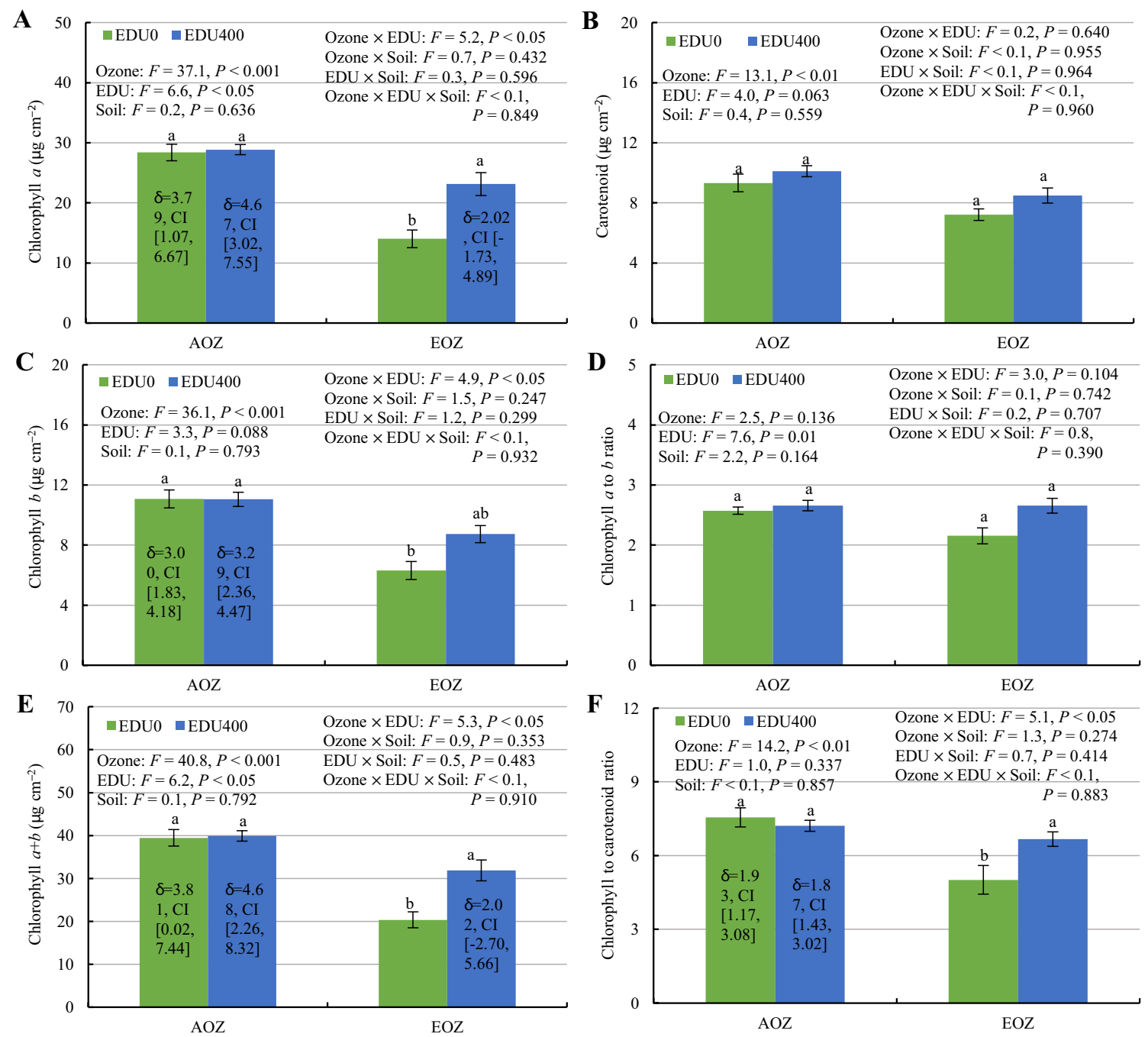

Fig. 11 Means $( \pm \mathrm{se}, n=6)$ of photosynthetic pigments of mature $\mathrm{O}_{3}$-symptomatic leaves of willow ( $\mathrm{S}$. sachalinensis) shrubs grown in brown forest (BF) or volcanic ash added to BF (VA-BF) soil, treated with 0 (EDU0) or 400 (EDU400) $\mathrm{mg} \mathrm{EDU} \mathrm{L}^{-1}$ every $9 \mathrm{~d}$, and exposed to either ambient (AOZ) or elevated (EOZ) ozone. Sampling was performed after gas exchange measurements in early September of the second growing season (2015). Data were analyzed with

Bonferroni, and no significant difference of biological importance for new shoot dry mass and total aboveground dry mass (i.e. only EOZ $\times$ EDU $400 \times$ VA-BF differed from $\mathrm{AOZ} \times \mathrm{EDU} 400 \times \mathrm{VA}-\mathrm{BF}$ and $\mathrm{AOZ} \times \mathrm{EDU} 0 \times \mathrm{BF})$.

Only $\mathrm{O}_{3}$ had a significant main effect on foliage damage by insects, which was $68.5 \pm 3.3 \%(n=12)$ in $\mathrm{AOZ}$ and $0.6 \pm 0.3 \%(n=12)$ in EOZ, indicating a large difference $(\delta=8.07, \mathrm{CI}[1.59,8.57])$. None of the other single factors or interactions were significant $(P>0.900$; data not shown). The insect damage observed was commonly destruction of leaf area (by chewer adult beetles of A. coerulea) or parenchyma eating (skeletonizer larvae of $A$. coerulea), thus reducing the photosynthesizing leaf area of plants.

a General Linear Model (GLM) at $\alpha=0.05$. For traits exhibiting a significant Ozone $\times$ EDU interaction, different letters above means indicate statistically significant differences between means based on Bonferroni post-hoc test $(\alpha=0.05)$. Cohen's delta $(\delta)$ and its confidence interval (CI) shown on a bar reflects the size of the difference between that group and the group $(\mathrm{EDU} 0 \times \mathrm{EOZ})$ from which it differs significantly based on Bonferroni results

\section{EDU and $\mathrm{O}_{3}$ carry-over effects following shoots harvest and cutting re-growth in the third growing season (2016)}

Ozone and EDU treatments in the previous growing seasons did not have any single or interactive effect on SPAD (Fig. 14A), LMA (Fig. 14B), $\mathrm{N}_{\mathrm{PPW}}$ (Fig. 14C), and $F_{v} / F_{m}$ (Fig. 14D) in mature leaves of newly developed shoots in September, 2016. This was also the case for the foliage damage caused by insect herbivores (average of all shoots per plant) (Fig. 15A). Shrubs re-grown from cuttings exposed to $\mathrm{EOZ}$ in the two previous growing seasons, however, had 2.3 times fewer adult beetles (A. coerulea) on their foliage 


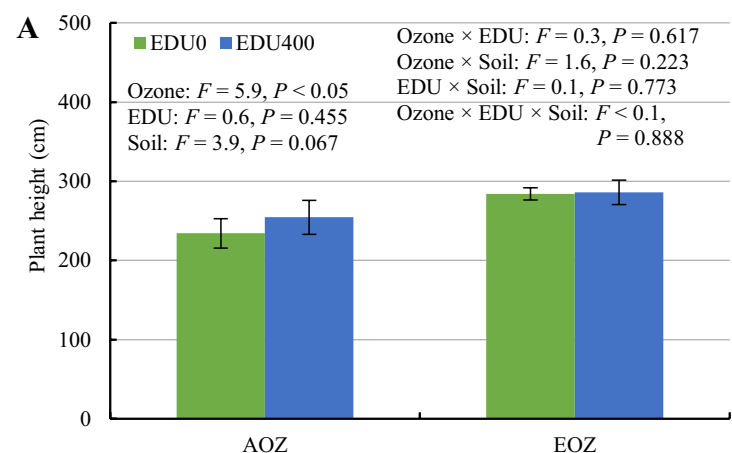

Fig. 12 Means $( \pm$ se, $n=6)$ of plant growth traits of willow ( $S$. sachalinensis) shrubs grown in brown forest (BF) or volcanic ash added to BF (VA-BF) soil, treated with 0 (EDU0) or 400 (EDU400) mg EDU $\mathrm{L}^{-1}$ every $9 \mathrm{~d}$, and exposed to either ambient (AOZ) or

(Fig. 15B), compared to AOZ group; this effect was marginally small $(\delta=0.50$, CI $[-4.92,6.20])$. There was no significant single or interactive effect of $\mathrm{O}_{3}$ and EDU treatments in the previous growing seasons on the average shoot height of re-grown shrubs (Fig. 16A). However, shrubs re-grown from cuttings exposed to EOZ in the two previous growing seasons had 1.2 and 1.3 times smaller average shoot basal diameter (Fig. 16B) and total aboveground dry mass (Fig. 16C) than shrubs re-grown from cuttings exposed to $\mathrm{AOZ}$ in the preceding growing seasons. This effect was small for both average shoot basal diameter $(\delta=0.83$, CI $[-0.17,2.65])$ and total aboveground biomass $(\delta=0.51, \mathrm{CI}$ $[-11.10,26.51])$.

\section{Discussion}

\section{Negligible influence of soil condition}

Through a multi-year, open-field experimentation, the effects of $\mathrm{O}_{3}$, soil type, and EDU on willow shrubs were studied at multiple levels. However, the effects of soil were negligible, especially as a function of $\mathrm{O}_{3}$ and EDU treatments. The absence of wide significant effects of soil may be explained by the fact that the addition of VA into the native soil was performed in the first $30 \mathrm{~cm}$ from the soil surface, while these very fast-growing shrubs were considerably big by the end of the first growing season, suggesting that their roots were deeper. Since there were negligible effects of soil, soil is excluded from the succeeding discussion.

\section{Ozone effects on plant physiology in the first growing season (2014)}

Visible injury appeared in leaves of various ages in EOZ, and the degree of severity was diverse. The injury was mainly

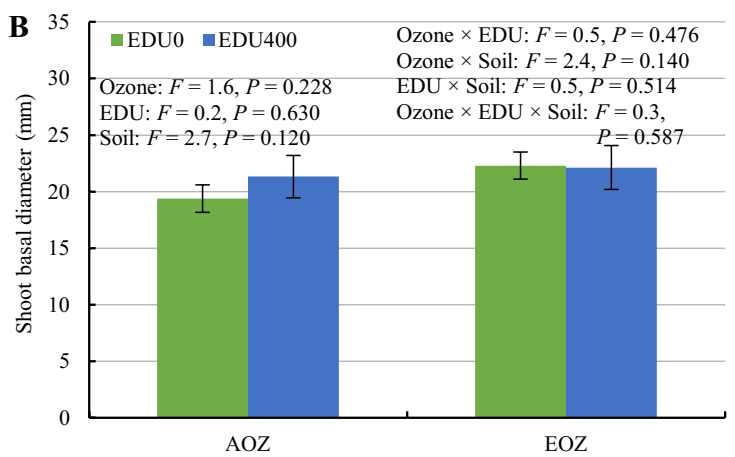

elevated (EOZ) ozone. Measurement was performed in mid. September of the second growing season (2015). Data were analyzed with a General Linear Model (GLM) at $\alpha=0.05$

discoloration of leaves, which eventually became yellowish and then brownish. Necrosis started from the peripheral leaf blade toward the central vein, and covered almost the entire interveinal spaces with progressing stress. These injuries are typical $\mathrm{O}_{3}$-induced foliar visible injuries, which have been observed in various plant species (Hoshika et al. 2013; Feng et al. 2014; Wan et al. 2014; Gottardini et al. 2014). The occurrence of foliar visible injuries, with decreased greenness, indicates that the shrubs grown in $\mathrm{EOZ}$ were under considerable $\mathrm{O}_{3}$-induced stress from the first growing season. However, such toxicities were mainly observed in older leaves, which were exposed to EOZ for a longer time, and evaluation of young top leaves revealed no significant effect of EOZ on SPAD and LMA. Leaf greenness and LMA are major determinants of $\mathrm{O}_{3}$ stress ( $\mathrm{Li}$ et al. 2017).

In young top leaves, $\mathrm{EOZ}$ increased $\mathrm{Mg}, \mathrm{Fe}$, and $\mathrm{Cr}$ and decreased $\mathrm{Mn}$ and Al. Because the effect of EOZ on Mn, $\mathrm{Fe}, \mathrm{Al}$, and $\mathrm{Cr}$ was moderate and on $\mathrm{Mg}$ large, it can be postulated that, among the studied elements, $\mathrm{Mg}$ played a more pronounced and dominant role in the mechanisms of plant stress response to $\mathrm{O}_{3}$. Across all treatments, $\mathrm{Mg}$ concentrations were negatively associated with $\mathrm{Fe}$ and $\mathrm{Al}$ and positively associated with $\mathrm{Cr}$, suggesting that the regulation of $\mathrm{Mg}$ depends upon $\mathrm{Fe}, \mathrm{Al}$, and $\mathrm{Cr}$. $\mathrm{Mg}$ is an important element in plant stress signaling, although its molecular and physiological roles have been neglected for a long time due to technical limitations (Guo et al. 2015). It also plays a vital role in the biosynthesis of chlorophylls and the fixation of carbon by acting as a cofactor of major enzymes participating in carbon metabolism (Hermans and Verbruggen 2005). Chlorophyll biosynthesis and carbon metabolism are major target sides of $\mathrm{O}_{3}$ stress, both of which are disturbed and inhibited by elevated $\mathrm{O}_{3}$ (Dizengremel et al. 1994; Dizengremel 2001; Feng et al. 2008, 2019b; Guidi et al. 2009; Pellegrini 2014; Kinose et al. 2020). The studies evaluating elemental composition in leaves of $\mathrm{O}_{3}$-treated trees are 

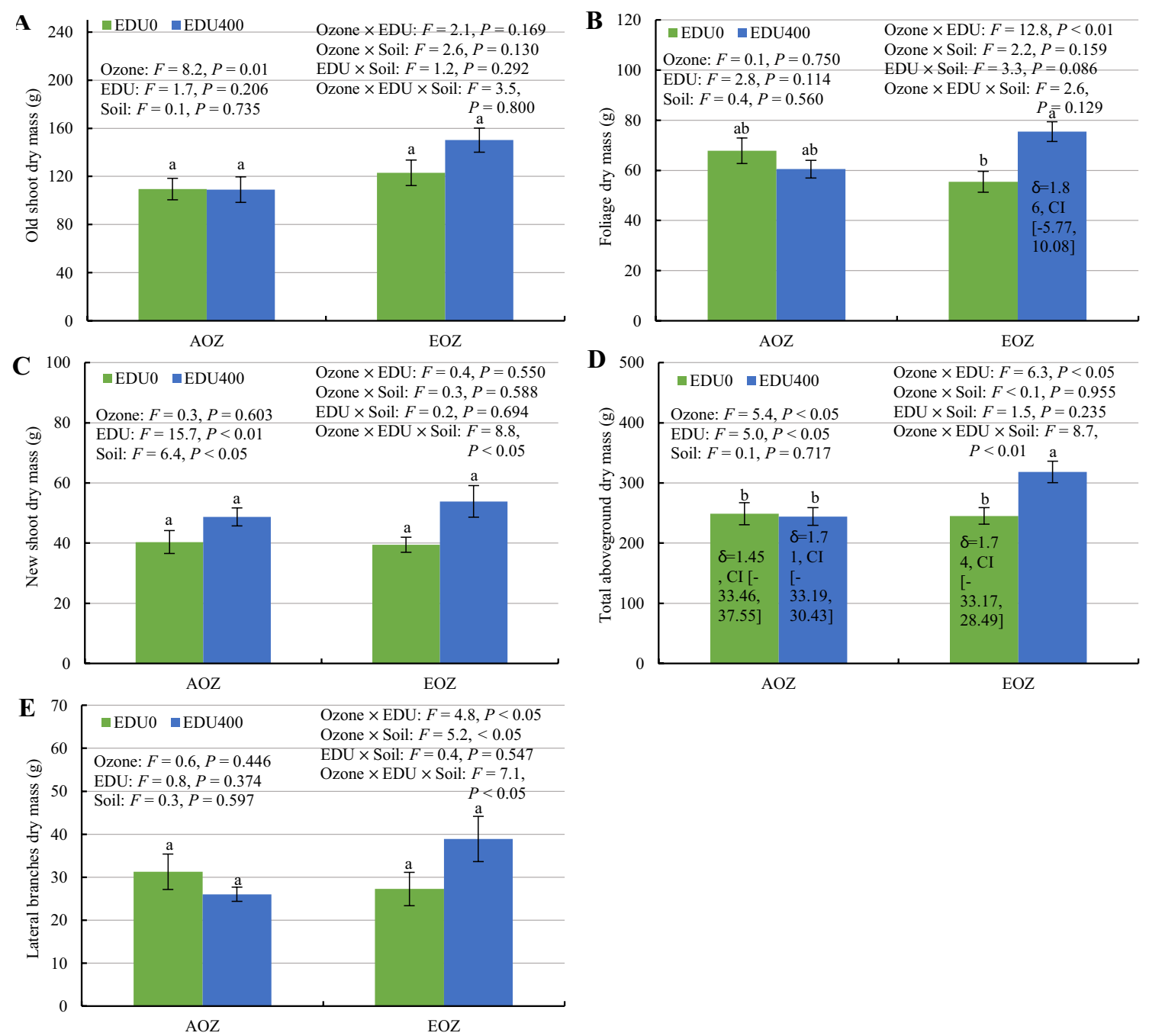

Fig. 13 Means $( \pm \mathrm{se}, n=6)$ of biomass production traits of willow (S. sachalinensis) shrubs grown in brown forest (BF) or volcanic ash added to BF (VA-BF) soil, treated with 0 (EDU0) or 400 (EDU400) mg EDU $\mathrm{L}^{-1}$ every $9 \mathrm{~d}$, and exposed to either ambient (AOZ) or elevated (EOZ) ozone. Old shoot is the part of the main shoot that was developed in 2014 (lignified in 2015), while new shoot is the part of the main shoot that was developed in 2015 (fresh/green). Harvest was performed in mid. September of the second growing season (2015). Data were analyzed with a General Linear Model (GLM) at $\alpha=0.05$.

limited, and the status of young, top leaves has rarely been studied because commonly the mature/older leaves are studied. Considering that chlorophylls have an $\mathrm{Mg}$ atom in the center of closed ring tetrapyroles, our study newly suggests that $\mathrm{Mg}$ in young top leaves may be enriched in the framework of a strategy to precondition new leaves so to protect them against $\mathrm{O}_{3}$-induced inhibition of chlorophylls; thus, keeping chlorophylls at 'normal' levels (no significant effect on SPAD was found) (Agathokleous 2021).

$\mathrm{Mg}$ contributes to plant health, and, in addition to its physiological benefits for active growth, is involved in plant resistance to diseases, such as protecting tissues

For traits exhibiting a significant Ozone $\times$ EDU interaction, different letters above means indicate statistically significant differences between means based on Bonferroni post-hoc test $(\alpha=0.05)$. Cohen's delta $(\delta)$ and its confidence interval (CI) shown on a bar reflects the size of the difference between that group and the group from which it differs significantly based on Bonferroni results. For the few significant Ozone $\times$ Soil and Ozone $\times$ EDU $\times$ Soil interaction, there was either no significant difference among means or there was no biologically meaningful significant difference among means

against degradation by pectolytic enzymes of some pathogens (Huber and Jones 2012). Our results extend these understandings by suggesting that $\mathrm{Mg}$ is also involved in the mechanisms of defense against $\mathrm{O}_{3}$ stress in this plant species. They also suggest that management of $\mathrm{Mg}$ nutrition may protect plants against $\mathrm{O}_{3}$ toxicities, a hypothesis that needs to be confirmed experimentally by exogenous application of various $\mathrm{Mg}$ concentrations. Although the interaction of soil $\mathrm{Mg}$ and $\mathrm{O}_{3}$ has been examined in loblolly pine (Pinus taeda L.) seedlings, only two $\mathrm{Mg}$ doses were included ( 12 or $35 \mu \mathrm{g} \mathrm{Mg} \mathrm{g}^{-1}$ ) and no significant treatments interaction was found (Edwards et al. 

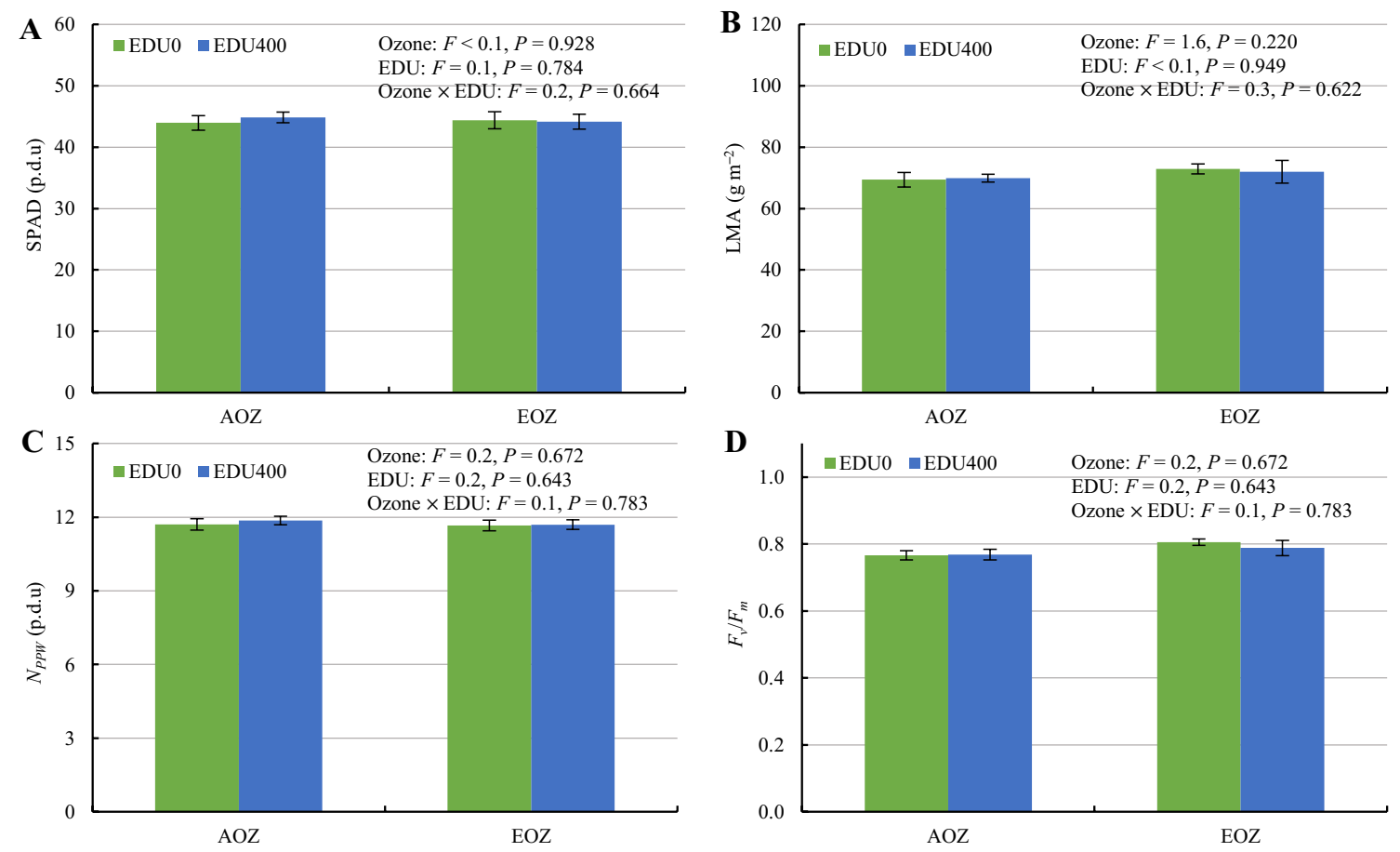

Fig. 14 Means ( \pm se, $n=5-15$ ) of biomass production traits of willow (S. sachalinensis) shrubs grown in brown forest $(\mathrm{BF})$ or volcanic ash added to BF (VA-BF) soil in 2014-2015, treated with 0 (EDU0) or 400 (EDU400) $\mathrm{mg} \mathrm{EDU} \mathrm{L}^{-1}$ every $9 \mathrm{~d}$ in 2015, and exposed to either ambient (AOZ) or elevated (EOZ) ozone in 2014-2015. Cuttings were transplanted into ambient plots newly created in 2016 and

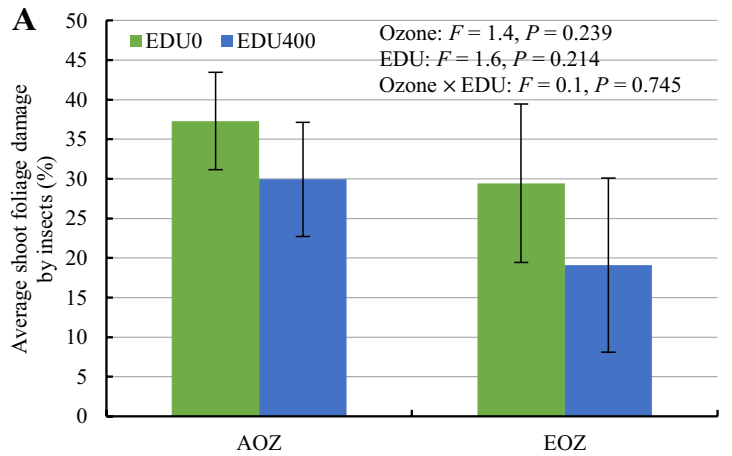

Fig. 15 Means ( \pm se, $n=5-15)$ of foliage damage by insect herbivores and number of adult beetles (Agelastica coerulea) in willow (S. sachalinensis) shrubs grown in brown forest (BF) or volcanic ash added to BF (VA-BF) soil in 2014-2015, treated with 0 (EDU0) or 400 (EDU400) mg EDU L ${ }^{-1}$ every $9 \mathrm{~d}$ in 2015, and exposed to

1990). Therefore, there is a need for more studies that will include several $\mathrm{Mg}$ doses to study the dose response under $\mathrm{O}_{3}$ stress. Previous studies with trees suggested that $\mathrm{O}_{3}$ alters the ecological stoichiometry (Agathokleous et al. 2018; Shang et al. 2018); however, the elements playing

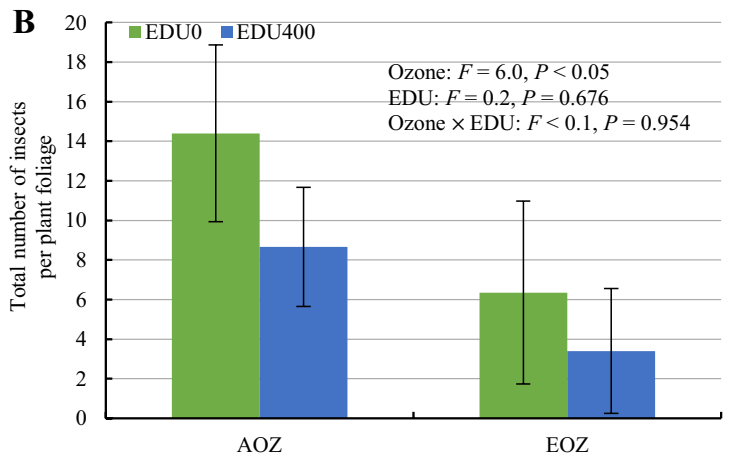

either ambient (AOZ) or elevated (EOZ) ozone in 2014-2015. Cuttings were transplanted into ambient plots newly created in 2016 and cultivated with no any treatments. Harvest of re-grown cuttings was performed in early October of the third growing season (2016). Data were analyzed with a General Linear Model (GLM) at $\alpha=0.05$

major roles in the responses seem to vary across species (Shi et al. 2017).

In fallen leaves, EOZ had a small effect on $\mathrm{Mg}$ (decrease) and $\mathrm{K}$ (increase), a moderate effect on $\mathrm{Mn}$ (decrease) and $\mathrm{P}$ (decrease), and a large effect on Al (decrease). The direction of the effect was opposite between young top leaves 

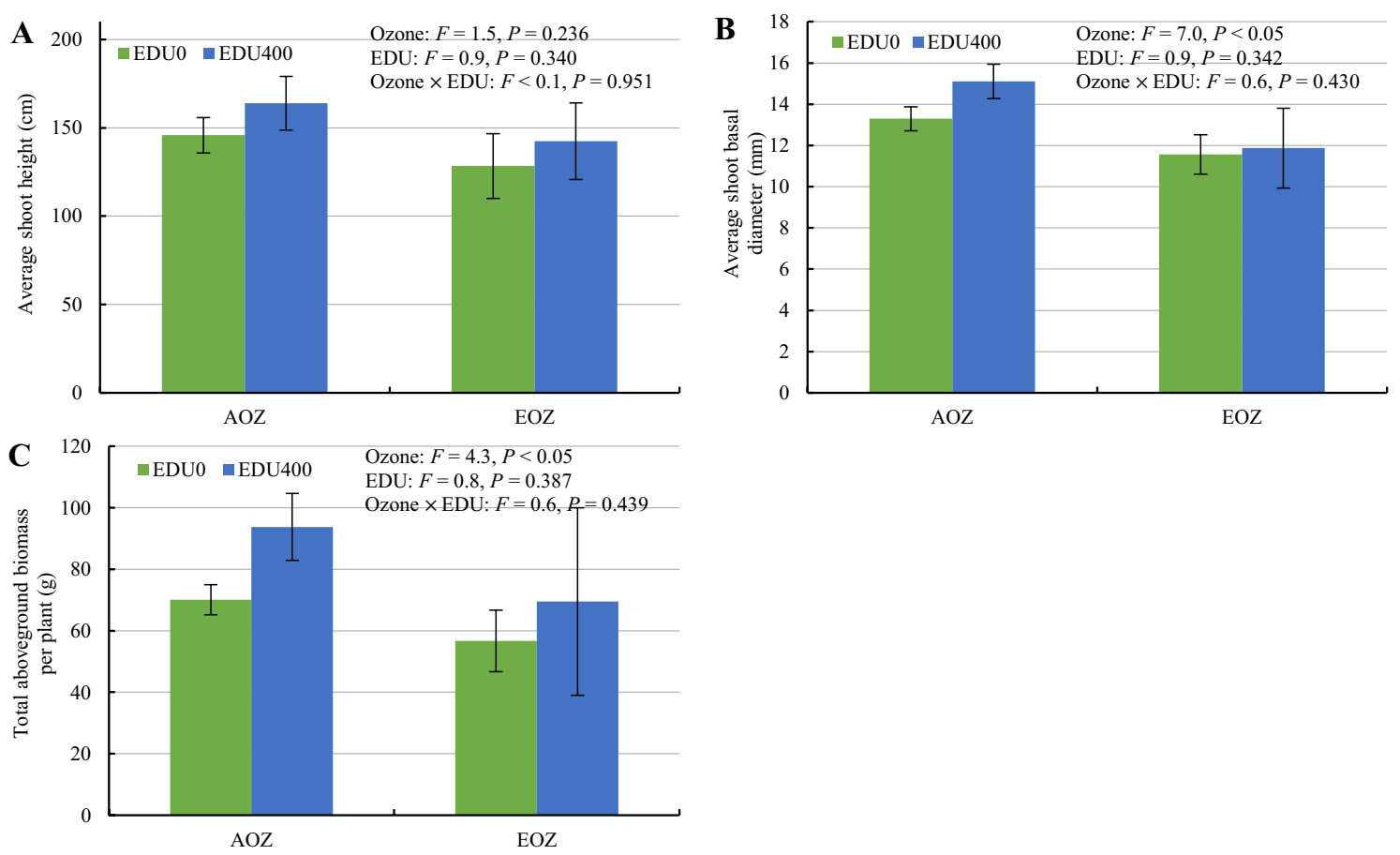

Fig. 16 Means ( \pm se, $n=5-15)$ of growth and biomass production traits of willow ( $S$. sachalinensis) shrubs grown in brown forest $(\mathrm{BF})$ or volcanic ash added to BF (VA-BF) soil in 2014-2015, treated with 0 (EDU0) or 400 (EDU400) $\mathrm{mg} \mathrm{EDU} \mathrm{L}^{-1}$ every $9 \mathrm{~d}$ in 2015, and exposed to either ambient (AOZ) or elevated (EOZ) ozone in 2014-

and fallen leaves for $\mathrm{Mg}$ and same for $\mathrm{Mn}$ and $\mathrm{Al}$. These results suggest that a greater amount of $\mathrm{Mg}$ might have been transferred to the young top leaves before shedding, thus contributing to the large increase in $\mathrm{Mg}$ in the young top leaves in EOZ. On the other hand, $\mathrm{Mn}$ and $\mathrm{Al}$ concentrations were decreased by EOZ in both fallen and top leaves, suggesting no significant contribution of elemental retranslocation from fallen to top leaves (e.g., Marschner 2012). However, because the decrease of $\mathrm{Mg}$ in fallen leaves was small whereas the increase in top leaves was large, some unidentified mechanisms might be involved in the enrichment of top leaves with $\mathrm{Mg}$, even if the mature senescing leaves may be proportionally more compared to the top leaves. For example, young leaves in this willow may act as a sink of $\mathrm{Mg}$ and carbon after activation of STAY-GREEN gene encoding Mg-dechelatase enzyme that catalyzes the reaction of extracting $\mathrm{Mg}$ from chlorophyll to synthesize phaeophytin (Shimoda et al. 2016; Sato et al. 2018). Whether root- or leaves-associated microorganisms (e.g., endophytes; Ueno et al. 2020, 2021) are involved in these mechanisms remains unknown and warrants further studies. Across all treatments, $\mathrm{Mg}$ was positively associated with $\mathrm{Fe}$ and $\mathrm{Ni}$, and negatively associated with $\mathrm{K}$ and $\mathrm{Cr}$ in fallen leaves, suggesting that the effect of $\mathrm{EOZ}$ on $\mathrm{Mg}$ can be driven by changes in $\mathrm{Fe}, \mathrm{Ni}$, $\mathrm{K}$, and $\mathrm{Cr}$. Nutrients $\mathrm{P}$ and $\mathrm{K}$ were significantly affected by

2015. Cuttings were transplanted into ambient plots newly created in 2016 and cultivated with no any treatments. Harvest of re-grown cuttings was performed in early October of the third growing season (2016). Data were analyzed with a General Linear Model (GLM) at $\alpha=0.05$

EOZ only in fallen leaves, while elements $\mathrm{Fe}$ and $\mathrm{Cr}$ were affected by EOZ only in young top leaves. These results indicate different effects of EOZ between the two leaf types. In a previous study with pot-grown cuttings of the same source with the ones used in this study, elevated $\mathrm{O}_{3}$ affected the cycling of $\mathrm{K}, \mathrm{Cr}, \mathrm{Fe}$, and $\mathrm{Ni}$ throughout crown, while it reduced the resorption efficiency of $\mathrm{Fe}$ and $\mathrm{Cr}$ and increased $\mathrm{P} / \mathrm{Fe}$ ratio (Agathokleous et al. 2018). Although $\mathrm{Ni}$ and $\mathrm{Fe}$ are microelements, they can cause nutritional imbalances with potentially negative effects on plants at high concentrations (Kayama et al. 2005). Moreover, Cr is often accumulated in roots and becomes harmful for plants at high concentrations, although some plants require trace amounts of $\mathrm{Cr}$ regulated by $\mathrm{Ca}$ (Marschner 2012). Most of $\mathrm{P}$ and $\mathrm{Fe}$ in soil exists in unavailable form, thus, plants absorb them by releasing some kinds of organic acids (or by associating with mycorrhizae) (Marschner 2012). Therefore, elemental imbalance in top and fallen leaves of $S$. sachalinensis due to EOZ might affect the expenditure of energy in an effort to return to homeostasis.

It was suggested that $\mathrm{Fe}$ homeostasis and $\mathrm{Cr}$ concentration regulation play an important role early in $\mathrm{O}_{3}$ stress; the assessment was conducted before leaves develop visible $\mathrm{O}_{3}$ symptoms (Agathokleous et al. 2018). Hence, the results of this study with tall shrubs grown directly onto the soil 
provide further support to the previous suggestions based on small pot-grown saplings.

\section{Ozone effects on plant growth and biomass production in early spring of the second growing season (2015)}

Plant growth and biomass production were evaluated in early spring of the second growing season, following snowmelt. Therefore, these growth and production characteristics reflect outcomes of the preceding growing season. All shoots, but one, produced by each plant in the first growing season were harvested to make possible the inclusion of EDU treatment in the study during the second growing season.

Despite the changes in elemental composition in leaves, which were observed in the first growing season, EOZ had no significant effect on the average length, basal diameter, number of lateral branches, and dry mass of branches per plant. However, EOZ caused a small increase in the total harvested aboveground biomass per plant. These results suggest physiological alterations at leaf level but no adverse effects of EOZ at individual plant level in the first growing season. Instead, that EOZ increased the total harvested aboveground biomass may indicate overcompensation responses of plant growth, similar to observations made in different species of trees exposed to elevated $\mathrm{O}_{3}$ (Kitao et al. 2015; Tobita et al. 2019). Although photosynthetic pigments were not directly measured in the first growing season, the large enrichment of $\mathrm{Mg}$ in top leaves by EOZ may relate to enhanced chlorophylls potential, and, thus, increased photosynthates that can lead to more biomass.

\section{EDU impact against $\mathrm{O}_{3}$ effects on plant physiology, growth, and biomass production in the second growing season (2015)}

The plasticity of LMA varies with plant functional groups and is an important determinant of plant fitness, affecting various ecosystem processes (Poorter et al. 2009). Deciduous shrubs and trees have smaller LMA than evergreen species (Poorter et al. 2009), and LMA is more affected by elevated $\mathrm{O}_{3}$ in deciduous broadleaved species than in evergreen broadleaf tree species ( $\mathrm{Li}$ et al. 2017). The range of LMA values found in mature leaves of the deciduous willow of this study is in line with the values reported for deciduous shrubs (on average $73 \mathrm{~g} \mathrm{~m}^{-2}$ ) and trees (on average $75 \mathrm{~g} \mathrm{~m}^{-2}$ ) in the literature (Poorter et al. 2009). However, that EDU400-treated leaves had moderately higher FM/DM value and lower LMA value than EDU0-treated leaves in EOZ suggests reduction of FM/DM and increase of LMA by EOZ, effects that were alleviated by EDU400. An increased LMA due to EOZ may indicate a mechanism to increase cell wall mass fraction and extend leaf lifespan at the expense of the efficiency of photosynthesis (Onoda et al. 2017). Although meta-analyses of woody species to $\mathrm{O}_{3}$ suggest a general decrease of LMA by considerably elevated $\mathrm{O}_{3}$ concentrations (83-128 $\mathrm{nmol} \mathrm{mol}^{-1}$; Li et al. (2017)), our study indicates that elevated $\mathrm{O}_{3}$-induced stress can have a positive effect on LMA. While a positive effect, the alleviation of this EOZ effect by EDU400 suggests the presence of oxidative stress induced by EOZ. The decreased FM/DM value by EOZ (or its increase by EDU400) may show that EOZ decreased the water content in mature leaves as a result of oxidative stress. Leaf water content is an important factor for insect herbivory (Bisigato et al. 2015), and one that had not been evaluated in previous studies of plant-insect interactions in this FACE system (Masui et al. 2021). However, since EDU400 led to a higher FM/DM value in EOZ while there was no difference in the herbivory between EDU400and EDU0-treated shrubs within EOZ, it can be postulated that leaf water content was not a major factor explaining the herbivory patterns.

The vast majority of studies investigated $\mathrm{O}_{3}$ effect on photosynthesis-related traits in symptomatic leaves. However, symptomatic leaves are expected to have considerably impacted photosynthetic apparatus due to the damaged chloroplast in leaves with $\mathrm{O}_{3}$-induced visible injury. Here, we found that EOZ had a small effect on gas exchange in $\mathrm{O}_{3}$-asymptomatic leaves too, in particular a decrease of $\mathrm{A}_{\max }$, which was counteracted by EDU400. The lack of significant effect of EOZ on $V_{C \max }$ and $J_{\max }$ as well as on gas exchange parameters other than $\mathrm{A}_{\max }$ suggests that EOZ had a rather biochemical mode of action in asymptomatic leaves. EDU400 also had a small effect on $A_{380}$ (increase) and $E_{380}$ (decrease) regardless of $\mathrm{O}_{3}$ treatment, suggesting that leaves in ambient $\mathrm{O}_{3}$ might also be under small stress. The small effect of EOZ on $A_{\max }$ is in agreement with its small negative effect on chlorophylls $a, b$, and $a+b$ and chlorophyll to carotenoid ratio in $\mathrm{O}_{3}$-asymptomatic leaves, effects against which EDU400 did not protect. The decrease in chlorophyll to carotenoid ratio by EOZ indicates that chlorophylls were relatively more affected by EOZ than carotenoids. Overall, despite no visible injuries, EOZ suppressed photosynthetic pigments, while EDU400 did not protect asymptomatic leaves against $\mathrm{O}_{3}$ by improving photosynthetic pigments. Conversely, based on well over 100 observations from several studies, EDU generally protects against $\mathrm{O}_{3}$-induced decrease in chlorophylls (Feng et al. 2010; Jiang et al. 2018; Gupta et al. 2021; Jabeen and Ahmed 2021; Chaudhary and Rathore 2021). However, the protection was genotype/ cultivar-specific (Jiang et al. 2018), and commonly chlorophylls were not evaluated in asymptomatic leaves. These observations suggest that EDU mode of action in protecting plants against $\mathrm{O}_{3}$-induced toxicity may differ between $\mathrm{O}_{3}$-symptomatic and $\mathrm{O}_{3}$-asymptomatic leaves. This assumption is further supported by the findings of photosynthetic 
pigments assessment in $\mathrm{O}_{3}$-symptomatic leaves. While $\mathrm{EOZ}$ $(\mathrm{EOZ} \times \mathrm{EDU} 0)$ caused a moderate $(\mathrm{vs} . \mathrm{EOZ} \times \mathrm{EDU} 400)$ to large (vs. AOZ $\times$ EDU0) decrease in chlorophyll $a$ and chlorophyll $a+b$ in $\mathrm{O}_{3}$-symptomatic leaves, EDU400 significantly protected to a moderate extent. However, the protective action of EDU in $\mathrm{O}_{3}$-symptomatic leaves was pigment-specific as EDU400 did not protect against EOZinduced reduction of carotenoids.

Despite the negative effects of EOZ on leaf-level physiology, EOZ-treated plants displayed a small increase in plant height, old shoot dry mass, and total aboveground dry mass, which may indicate overcompensation responses similar to the biomass production of the first growing season and observations in different studies with other species exposed to elevated $\mathrm{O}_{3}$ (Kitao et al. 2015; Tobita et al. 2019). Contrariwise, EDU400 increased new shoot dry mass and total aboveground dry mass, compared EDU0-treated plants, irrespective of $\mathrm{O}_{3}$ treatment, a finding suggesting that shrubs in both $\mathrm{AOZ}$ and EOZ were under stress. Moreover, the moderate increase in foliage dry mass noted in EDU400treated shrubs, compared to EDU0-treated shrubs, within EOZ suggests that EDU400 protected against EOZ-induced premature senescence and/or directly increased total leaf area. As a result of the individual biomass components responses, EDU $400 \times \mathrm{EOZ}$ treatment led to a small to moderate increase of total aboveground dry mass compared to $\mathrm{EDU} 0 \times \mathrm{EOZ}, \mathrm{EDU} 0 \times \mathrm{AOZ}$, and $\mathrm{EDU} 400 \times \mathrm{AOZ}$ treatments, suggesting that plants of EDU $400 \times \mathrm{EOZ}$ treatment were more vigorous/productive than plants of the other treatment combinations.

Because it was observed during routine field work that insect herbivore activity and thus herbivory were considerably lower in EOZ plots than in AOZ plots, foliage damage by insects was recorded. The large destruction of leaf area by chewer adult beetles and parenchyma eating by larvae observed in $\mathrm{AOZ}$ plots, while it was negligible in EOZ plots, is in agreement with extensive observations in different plant species in the same plots from 2014 to 2016 (Masui et al. 2021). Since this difference in herbivory was irrespective of EDU treatment, this study further indicates that the difference in herbivory between $\mathrm{AOZ}$ and $\mathrm{EOZ}$ plots is primarily not due to plant qualitative status but rather due to atmospheric status, further hinting to a potentially more important role of volatile organic compounds in mediating insect-plant communication (Blande 2021; Masui et al. 2021). Within EOZ, there was negligible damage by herbivores, indicating that $\mathrm{O}_{3}$ was the plant-inhibiting factor. The widespread herbivory in AOZ, by imposing stress to plants, may also explain the small increase in $A_{380}$ and decrease in $E_{380}$ by EDU400 irrespective of $\mathrm{O}_{3}$ treatment. EDU is widely used as an $\mathrm{O}_{3}$ biomonitoring tool and chemical to attribute differences between EDU-treated and -untreated plants to $\mathrm{O}_{3}$ (Manning et al. 2011; Yuan et al. 2015; Singh et al. 2018;
Pandey et al. 2019; Fatima et al. 2019; Giovannelli et al. 2019). Hence, plants treated with EDU400 in EOZ can be considered as a control that theoretically approximates plant status under no $\mathrm{O}_{3}$ stress. By comparison, response of plants treated with EDU0 in EOZ represents the effect of EOZ when compared with plants treated with EDU400 in EOZ. Moreover, the response of plants treated with either EDU0 or EDU400 in AOZ represents the effect of herbivory when compared with plants treated with EDU400 in EOZ. Hence, both EOZ and herbivory in AOZ suppressed biomass production. The increased biomass produced in the first growing season in EOZ might also be the result of largely more severe herbivory of AOZ plants compared to EOZ plants, instead of being positive effects of EOZ. This is highly plausible since similar herbivory patterns were observed in this exposure system in the first growing season, although not monitored in these willow shrubs (Masui et al. 2021). These results suggest that herbivory complicated $\mathrm{O}_{3}$ effects estimation, highlighting the need to consider herbivory when evaluating $\mathrm{O}_{3}$ effects on vegetation as well as the importance of FACE experimentation in providing more realistic evaluation of $\mathrm{O}_{3}$ effects on vegetation by permitting consideration of biotic interactions. Many of the results could lead to incorrect conclusions if EDU were not included in the second growing season, indicating that EDU can be incorporated into such FACE studies as a tool to account for potential differences between $\mathrm{O}_{3}$ treatments due to factors other than $\mathrm{O}_{3}$.

\section{EDU and $\mathrm{O}_{3}$ carry-over effects following shoots harvest and cutting re-growth in the third growing season (2016)}

Ratoon cropping is a cultivation technique applied in the agronomical practice of various crops since a long time ago (Plucknett et al. 1970; Wang et al. 2020). New shoots (ratoon) emerge from the base of a plant following cropping, a practice that facilitates green and resource-efficient production (Wang et al. 2020). In this study, ratoon cropping was applied for the first time to investigate potential treatment effects on ratoon developed in the third growing season without the ratoon being directly exposed to elevated $\mathrm{O}_{3}$ or EDU. To this end, harvested cuttings with their root system were transplanted into new ambient sites after snowmelt in the third growing season.

$\mathrm{O}_{3}$ and EDU treatments in the previous years did not significantly affect leaf-level physiology (SPAD, $N_{P P W}$, LMA, and $\left.F_{v} / F_{m}\right)$ in the current year, suggesting no carry-over and/ or memory effects. However, while the average foliage damage by insect herbivores was also not significantly affected by the $\mathrm{O}_{3}$ and EDU treatments in the previous years, shrubs re-grown from cuttings exposed to EOZ in the two previous growing seasons had fewer $A$. coerulea adult individuals on their foliage, compared to $\mathrm{AOZ}$ group, irrespective 
of EDU treatment. This suggests that (1) leaves on ratoon developed from cuttings/roots previously exhibiting to EOZ stress might be less attractive to insects, and (2) some unidentified biochemical alterations (e.g., in secondary metabolites concentrations) might be present in leaves of ratoon developed from cuttings/roots subjected to EOZ stress in the preceding two years. Furthermore, shrubs re-grown from cuttings exposed to EOZ in the two previous growing seasons exhibited a small inhibition of average shoot basal diameter and total aboveground dry mass, compared to AOZ group, irrespective of EDU treatment. Therefore, the negative effect of EOZ on biomass production of this energy crop $($ EDU0 $\times$ EOZ vs. EDU400 $\times$ EOZ) was carried over in the third growing season, which may be due to inhibition of root by EOZ in the previous years (Grantz et al. 2006). The results of these assessments suggest a carry-over effect. A potential memory effect through signals generated or processed in the cutting and/or root cannot be excluded either. It should be supplemented here that a recent study also provides evidence suggestive of the generation and/or process of signals in the root involved in transgenerational effects of oxidative stress, specifically by Cd (Nogueira et al. 2021). Therefore, further experimentation is needed to reveal whether carry-over and/or memory effects of $\mathrm{O}_{3}$ are primarily driven by roots.

\section{Conclusion}

In the first growing season, the interactive effects of $\mathrm{O}_{3}$ and soil were studied; however, soil had negligible impact on $\mathrm{O}_{3}$ effects. EOZ led to various alterations in the leaf elemental composition. Specifically, among the evaluated elements, a predominant role of $\mathrm{Mg}$ was revealed. Although $\mathrm{Mg}$ exhibited a small decrease by EOZ in fallen leaves, it was largely enriched by EOZ in young top leaves. This novel finding suggests a mechanism to condition young top leaves, potentially to prevent $\mathrm{O}_{3}$-induced suppression of chlorophylls, and warrants further studies to investigate whether exogenous application of $\mathrm{Mg}$ can protect plants against elevated $\mathrm{O}_{3}$-induced phytotoxicity. EOZ exposure resulted in considerable changes in the elemental composition of young top leaves and fallen leaves, suggesting altered ecological stoichiometry. Such elemental changes can have implications to ecological processes such as litter decomposition.

In the second growing season, EDU was added in the experimental design. EDU400 protected against EOZ-induced reduction of FM/DM and LMA in randomly-selected mature leaves as well as of $A_{\max }$ in $\mathrm{O}_{3}$-asymptomatic leaves. EDU400, however, did not protect against EOZ-induced suppression of $V_{C \max }, J_{\text {max }}$, and chlorophylls $a, b$, and $a+b$ in $\mathrm{O}_{3}$-asymptomatic leaves. The mode of action of EDU in $\mathrm{O}_{3}$-asymptomatic leaves differed from $\mathrm{O}_{3}$-symptomatic leaves in which EDU400 protected against EOZ-induced suppression of chlorophyll $a$ and chlorophyll $a+b$, indicating that the mode of action of EDU may vary with the severity of $\mathrm{O}_{3}$-induced stress in the leaf. Despite the negative effects of EOZ on leaf-level physiology, shrubs grown in EOZ produced more biomass than shrubs grown in AOZ. Based on consideration of shrubs performance under EDU treatment and herbivory, both EOZ and insect herbivore-induced damage in AOZexposed shrubs resulted in suppression of biomass production. These results signify the profound importance of considering biotic interactions when assessing $\mathrm{O}_{3}$ effects on vegetation.

In the third growing season, carry-over effects of treatments were studied following ratoon cropping and transplantation of all plants into new ambient plots. EOZ treatment in the preceding growing seasons imposed a carry-over effect as indicated by suppressed ratoon biomass production. EDU400 treatment in the preceding growing season did not protect against EOZ carry-over effect, indicating that such an intervention based on hormesis priming should be applied in each growing season in ratoon cropping systems to protect plants against $\mathrm{O}_{3}$-induced phytotoxicities.

We conclude that EOZ can adversely affect willow shrubs cultivated as energy crops, with long-lasting impacts, whereas EDU can enhance plant physiological performance and biomass production. Further work is needed to translate these scientific results into practical applications under realworld cropping systems.

Acknowledgements The authors are thankful to Mr. Tatsushiro Ueda (engineer; Dalton Co., Hokkaido Branch, Japan) for assistance in regulating the $\mathrm{O}_{3}$-exposure system throughout the experiment, as well as to lab member Ms. Sayako Kanie for contribution in the gas exchange measurements. They also thank Dr. William J. Manning, Emer. Prof. at the University of Massachusetts, Amherst, USA, for kindly providing ethylenediurea. E.A. is grateful to Dr. Marina Frontasyeva of the Frank Laboratory of Neutron Physics, Joint Institute for Nuclear Research, Dubna, Russian Federation, for the invitation to participate in and present at the 29th Task Force Meeting of the UNECE ICP Vegetation, 29 February - 4 March, 2016, Dubna, Russian Federation. E.A acknowledges multi-year support from The Startup Foundation for Introducing Talent of Nanjing University of Information Science \& Technology (NUIST), Nanjing, China (Grant No. 003080).

\section{Declarations}

Conflict of interest Evgenios Agathokleous (E.A.) is Associate Editor-in-Chief of this journal; however, he was not involved in the peer-review process of this manuscript. Parts of this research were presented in talks given by the first author (E.A.): (i) at the IUFRO's Regional Congress for Asia and Oceania 2016 "Air pollution and climate change impacts on forest ecosystems", 24-27 October, 2016, Beijing, People's Republic of China; (ii) at the 29th Task Force Meeting of the UNECE ICP Vegetation, 29 February-4 March, 2016, Dubna, Russian Federation; (iii) at the 3rd International Life-Science Symposium, 26 November, 2015, Sapporo, Japan; (iv) at the 126th Annual meeting of Japan Forest Society, 27-29 March, 2015, Sapporo, Japan. The at- 
tendance of E.A. to present was financially supported by JSPS (event i) and the Frank Laboratory of Neutron Physics, Joint Institute for Nuclear Research, Dubna, Russian Federation (event ii). The authors declare that there are no conflicts of interest.

Open Access This article is licensed under a Creative Commons Attribution 4.0 International License, which permits use, sharing, adaptation, distribution and reproduction in any medium or format, as long as you give appropriate credit to the original author(s) and the source, provide a link to the Creative Commons licence, and indicate if changes were made. The images or other third party material in this article are included in the article's Creative Commons licence, unless indicated otherwise in a credit line to the material. If material is not included in the article's Creative Commons licence and your intended use is not permitted by statutory regulation or exceeds the permitted use, you will need to obtain permission directly from the copyright holder. To view a copy of this licence, visit http://creativecommons.org/licenses/by/4.0/.

\section{References}

Adegbidi HG, Volk TA, White EH, Abrahamson LP, Briggs RD, Bickelhaupt DH (2001) Biomass and nutrient removal by willow clones in experimental bioenergy plantations in New York state. Biomass Bioenerg 20:399-411. https://doi.org/10.1016/ S0961-9534(01)00009-5

Agathokleous E (2017) Perspectives for elucidating the ethylenediurea (EDU) mode of action for protection against $\mathrm{O}_{3}$ phytotoxicity. Ecotoxicol Environ Saf 142:530-537. https://doi.org/10. 1016/j.ecoenv.2017.04.057

Agathokleous E (2021) The rise and fall of photosynthesis: hormetic dose response in plants. J for Res 32:789-803. https://doi.org/ 10.1007/s 11676-020-01252-1

Agathokleous E, Saitanis CJ (2020) Plant susceptibility to ozone: a tower of babel? Sci Total Environ 703:134962. https://doi.org/ 10.1016/j.scitotenv.2019.134962

Agathokleous E, Koike T, Watanabe M, Hoshika Y, Saitanis CJ (2015) Ethylene-di-urea (EDU), an effective phytoproctectant against $\mathrm{O}_{3}$ deleterious effects and a valuable research tool. $\mathrm{J}$ Agric Meteorol 71:185-195. https://doi.org/10.2480/agrmet. D-14-00017

Agathokleous E, Paoletti E, Saitanis CJ, Manning WJ, Shi C, Koike $\mathrm{T}$ (2016a) High doses of ethylene diurea (EDU) are not toxic to willow and act as nitrogen fertilizer. Sci Total Environ 566567:841-850. https://doi.org/10.1016/j.scitotenv.2016.05.122

Agathokleous E, Paoletti E, Saitanis CJ, Manning WJ, Sugai T, Koike T (2016b) Impacts of ethylenediurea (EDU) soil drench and foliar spray in Salix sachalinensis protection against $\mathrm{O}_{3}$-induced injury. Sci Total Environ 573:1053-1062. https:// doi.org/10.1016/j.scitotenv.2016.08.183

Agathokleous E, Saitanis CJ, Stamatelopoulos D, Mouzaki-Paxinou A-C, Paoletti E, Manning WJ (2016c) Olive oil for dressing plant leaves so as to avoid $\mathrm{O}_{3}$ injury. Water Air Soil Pollut 227:282. https://doi.org/10.1007/s11270-016-2986-9

Agathokleous E, Kitao M, Chu Q, Saitanis CJ, Paoletti E, Manning WJ, Watanabe T, Koike T (2018) Effects of ozone $\left(\mathrm{O}_{3}\right)$ and ethylenediurea (EDU) on the ecological stoichiometry of a willow grown in a free-air exposure system. Environ Pollut 238:663-676. https://doi.org/10.1016/j.envpol.2018.03.061

Agathokleous E, Kitao M, Koike T (2021a) Ethylenediurea (EDU) effects on hybrid larch saplings exposed to ambient or elevated ozone over three growing seasons. J for Res In Press. https:// doi.org/10.1007/s11676-021-01352-6
Agathokleous E, Kitao M, Wang X, Mao Q, Harayama H, Manning WJ, Koike T (2021b) Ethylenediurea (EDU) effects on Japanese larch: an one growing season experiment with simulated regenerating communities and a four growing season application to individual saplings. J for Res 32:2047-2057. https://doi. org/10.1007/s11676-020-01223-6

Akimoto H, Mori Y, Sasaki K, Nakanishi H, Ohizumi T, Itano Y (2015) Analysis of monitoring data of ground-level ozone in Japan for longterm trend during 1990e2010: Causes of temporal and spatial variation. Atmos Emviron 102:302-310. https:// doi.org/10.1016/j.atmosenv.2014.12.001

Ashrafuzzaman M, Haque Z, Ali B, Mathew B, Yu P, Hochholdinger F, de Abreu Neto JB, McGillen MR, Ensikat HJ, Manning WJ, Frei M (2018) Ethylenediurea (EDU) mitigates the negative effects of ozone in rice: Insights into its mode of action. Plant Cell Environ 41:2882-2898. https://doi.org/10.1111/pce.13423

Barnes JD, Balaguer L, Manrique E, Elvira S, Davison AW (1992) A reappraisal of the use of DMSO for the extraction and determination of chlorophylls $a$ and $b$ in lichens and higher plants. Environ Exp Bot 32:85-100. https://doi.org/10.1016/00988472(92)90034-y

Bisigato AJ, Saín CL, Campanella MV (2015) Cheli GH (2015) Leaf traits, water stress, and insect herbivory: is food selection a hierarchical process? Arthropod-Plant Interact 95(9):477-485. https://doi.org/10.1007/S11829-015-9387-7

Blande JD (2021) Effects of air pollution on plant-insect interactions mediated by olfactory and visual cues. Curr Opin Environ Sci Heal 19:100228. https://doi.org/10.1016/j.coesh.2020.100228

Carnahan JE, Jenner EL, Wat EKW (1978) Prevention of ozone injury to plants by a new protectant chemical. Phytopathology 68:225-1229

Chaudhary IJ, Rathore D (2021) Assessment of dose-response relationship between ozone dose and groundnut (Arachis hypogaea $\mathrm{L}$ ) cultivars using Open Top Chamber (OTC) and Ethylenediurea (EDU). Environ Technol Innov 22:101494. https://doi.org/10. 1016/j.eti.2021.101494

Cohen J (1988) Statistical power analysis for the behavioral sciences. Lawrence Erlbaum Associates, New Jersey, p 590

Cotrozzi L (2021) The effects of tropospheric ozone on oaks: a global meta-analysis. Sci Total Environ 756:143795. https://doi.org/10. 1016/j.scitotenv.2020.143795

Derstroff B, Hüser I, Bourtsoukidis E, Crowley JN, Fischer H, Gromov S, Harder H, Janssen RHH, Kesselmeier J, Lelieveld J, Mallik C, Martinez M, Novelli A, Parchatka U, Phillips GJ, Sander R, Sauvage C, Schuladen J, Stönner C, Tomsche L, Williams J (2017) Volatile organic compounds (VOCs) in photochemically aged air from the eastern and western Mediterranean. Atmos Chem Phys 17:9547-9566. https://doi.org/10.5194/acp-17-9547-2017

Dimitriou I, Baum C, Baum S, Busch G, Schulz U, Köhn J, Lamersdorf N, Leinweber P, Aronsson P, Weih M, Berndes G, Bolte A (2011) Quantifying environmental effects of short rotation coppice (SRC) on biodiversity, soil and water. In: IEA Bioenergy, Task 43: Biomass Feedstock for Energy Markets. p 33

Dizengremel P (2001) Effects of ozone on the carbon metabolism of forest trees. Plant Physiol Biochem 39:729-742. https://doi.org/ 10.1016/S0981-9428(01)01291-8

Dizengremel P, Sasek TW, Brown KJ, Richardson CJ (1994) Ozoneinduced changes in primary carbon metabolism enzymes of loblolly pine needles. J Plant Physiol 144:300-306. https://doi. org/10.1016/s0176-1617(11)81191-0

Edwards NT, Taylor GE, Adams MB, Simmons GL, Kelly JM (1990) Ozone, acidic rain and soil magnesium effects on growth and foliar pigments of Pinus taeda L. Tree Physiol 6:95-104. https:// doi.org/10.1093/treephys/6.1.95 
El Kasmioui O, Ceulemans R (2012) Financial analysis of the cultivation of poplar and willow for bioenergy. Biomass Bioenerg 43:52-64. https://doi.org/10.1016/j.biombioe.2012.04.006

Erickson LE, Newmark GL, Higgins MJ, Wang Z (2020) Nitrogen oxides and ozone in urban air: A review of 50 plus years of progress. Environ Prog Sustain Energy 39:39. https://doi.org/ 10.1002/ep. 13484

Fabio ES, Kemanian AR, Montes F, Miller RO, Smart LB (2017) A mixed model approach for evaluating yield improvements in interspecific hybrids of shrub willow, a dedicated bioenergy crop. Ind Crops Prod 96:57-70. https://doi.org/10.1016/j.indcr op.2016.11.019

Farquhar GD, von Caemmerer S, Berry JA (1980) A biochemical model of photosynthetic $\mathrm{CO}_{2}$ assimilation in leaves of $\mathrm{C}_{3}$ species. Planta 149:78-90. https://doi.org/10.1007/bf00386231

Fatima A, Singh AA, Mukherjee A, Dolker T, Agrawal M, Agrawal SB (2019) Assessment of ozone sensitivity in three wheat cultivars using ethylenediurea. Plants 8:80. https://doi.org/10.3390/plant s8040080

Fenech S, Aquilina NJ, Vella R (2021) COVID-19-related changes in $\mathrm{NO}_{2}$ and $\mathrm{O}_{3}$ concentrations and associated health effects in Malta. Front Sustain Cities 3:631280. https://doi.org/10.3389/ frsc. 2021.631280

Feng Z, Kobayashi K, Ainsworth EA (2008) Impact of elevated ozone concentration on growth, physiology, and yield of wheat (Triticum aestivum L.): a meta-analysis. Glob Chang Biol 14:26962708. https://doi.org/10.1111/j.1365-2486.2008.01673.x

Feng Z, Wang S, Szantoi Z, Chen S, Wang X (2010) Protection of plants from ambient ozone by applications of ethylenediurea (EDU): a meta-analytic review. Environ Pollut 158:3236-3242. https://doi.org/10.1016/j.envpol.2010.07.009

Feng Z, Sun J, Wan W, Hu E, Calatayud V (2014) Evidence of widespread ozone-induced visible injury on plants in Beijing, China. Environ Pollut 193:296-301. https://doi.org/10.1016/j.envpol. 2014.06.004

Feng Z, De Marco A, Anav A, Gualtieri M, Sicard P, Tian H, Fornasier F, Tao F, Guo A, Paoletti E (2019a) Economic losses due to ozone impacts on human health, forest productivity and crop yield across China. Environ Int 131:104966. https://doi.org/10. 1016/j.envint.2019.104966

Feng Z, Shang B, Gao F, Calatayud V (2019b) Current ambient and elevated ozone effects on poplar: A global meta-analysis and response relationships. Sci Total Environ 654:832-840. https:// doi.org/10.1016/j.scitotenv.2018.11.179

Gao M, Gao J, Zhu B, Kumar R, Lu X, Song S, Zhang Y, Jia B, Wang P, Beig G, Hu J, Ying Q, Zhang H, Sherman P, McElroy MB (2020) Ozone pollution over China and India: seasonality and sources. Atmos Chem Phys 20:4399-4414. https://doi.org/10. 5194/acp-20-4399-2020

Giovannelli A, Traversi ML, Anichini M, Hoshika Y, Fares S, Paoletti E (2019) Effect of long-term vs. short-term ambient ozone exposure on radial stem growth, sap flux and xylem morphology of $\mathrm{O}_{3}$-sensitive poplar trees. Forests 10:396. https://doi.org/10. 3390/f10050396

Gottardini E, Cristofolini F, Cristofori A, Ferretti M (2014) Ozone risk and foliar injury on Viburnum lantana L.: a meso-scale epidemiological study. Sci Total Environ 493:954-960. https://doi.org/ 10.1016/j.scitotenv.2014.06.041

Grantz DA, Gunn S, Vu H-B (2006) $\mathrm{O}_{3}$ impacts on plant development: a meta-analysis of root/shoot allocation and growth. Plant Cell Environ 29:1193-1209. https://doi.org/10.1111/j.1365-3040. 2006.01521.x

Guidi L, Degl'Innocenti E, Martinelli F, Piras M (2009) Ozone effects on carbon metabolism in sensitive and insensitive Phaseolus cultivars. Environ Exp Bot 66:117-125. https://doi.org/10.1016/j. envexpbot.2008.12.005
Guidi Nissim W, Pitre FE, Teodorescu TI, Labrecque M (2013) Longterm biomass productivity of willow bioenergy plantations maintained in southern Quebec, Canada. Biomass Bioenerg 56:361369. https://doi.org/10.1016/j.biombioe.2013.05.020

Guo W, Chen S, Hussain N, Cong Y, Liang Z, Chen K (2015) Magnesium stress signaling in plant: just a beginning. Plant Signal Behav 10:e992287. https://doi.org/10.4161/15592324.2014. 992287

Gupta SK, Sharma M, Maurya VK, Deeba F, Pandey V (2021) Effects of ethylenediurea (EDU) on apoplast and chloroplast proteome in two wheat varieties under high ambient ozone: an approach to investigate EDU's mode of action. Protoplasma 258:1009-1028. https://doi.org/10.1007/s00709-021-01617-1

Hermans C, Verbruggen N (2005) Physiological characterization of Mg deficiency in Arabidopsis thaliana. J Exp Bot 56:2153-2161. https://doi.org/10.1093/jxb/eRI215

Hoshika Y, Pecori F, Conese I, Bardelli T, Marchi E, Manning WJ, Badea O, Paoletti E (2013) Effects of a three-year exposure to ambient ozone on biomass allocation in poplar using ethylenediurea. Environ Pollut 180:299-303. https://doi.org/10.1016/j. envpol.2013.05.041

Huber DM, Jones JB (2012) The role of magnesium in plant disease. Plant Soil 20123681 368:73-85. https://doi.org/10.1007/ s11104-012-1476-0

Jabeen F, Ahmed S (2021) Ethylenediurea regulates growth and physiochemical responses of Pisum sativum to ambient $\mathrm{O}_{3}$. Int J Environ Sci Technol 2021:1-10. https://doi.org/10.1007/ S13762-020-03077-1

Jiang L, Feng Z, Dai L, Shang B, Paoletti E (2018) Large variability in ambient ozone sensitivity across 19 ethylenediurea-treated Chinese cultivars of soybean is driven by total ascorbate. $\mathrm{J}$ Environ Sci 64:10-22. https://doi.org/10.1016/j.jes.2017.07. 002

Jolivet Y, Bagard M, Cabané M, Vaultier M-N, Gandin A, Afif D, Dizengremel P, Le Thiec D (2016) Deciphering the ozone-induced changes in cellular processes: a prerequisite for ozone risk assessment at the tree and forest levels. Ann for Sci 73:923-943. https://doi.org/10.1007/s13595-016-0580-3

Kakuk B, Bagi Z, Rákhely G, Maróti G, Dudits D, Kovács KL (2021) Methane production from green and woody biomass using short rotation willow genotypes for bioenergy generation. Bioresour Technol 333:125223. https://doi.org/10.1016/j.biortech.2021. 125223

Karnosky DF, Skelly JM, Percy KE, Chappelka AH (2007a) Perspectives regarding 50 years of research on effects of tropospheric ozone air pollution on US forests. Environ Pollut 147:489-506. https://doi.org/10.1016/j.envpol.2006.08.043

Karnosky DF, Werner H, Holopainen T, Percy K, Oksanen T, Oksanen E, Heerdt C, Fabian P, Nagy J, Heilman W, Cox R, Nelson N, Matyssek R (2007b) Free-air exposure systems to scale up ozone research to mature trees. Plant Biol 9:181-190. https://doi.org/ 10.1055/s-2006-955915

Karp A, Hanley SJ, Trybush SO et al (2011) Genetic improvement of willow for bioenergy and biofuels. J Integr Plant Biol 53:151165. https://doi.org/10.1111/j.1744-7909.2010.01015.x

Kayama M, Quoreshi AM, Uemura S, Koike T (2005) Differences in growth characteristics and dynamics of elements absorbed in seedlings of three spruce species raised on serpentine soil in northern Japan. Ann Bot 95:661-672. https://doi.org/10.1093/ aob/mci063

Kinose Y, Fukamachi Y, Okabe S, Hiroshima H, Watanabe M, Izuta T (2020) Toward an impact assessment of ozone on plant carbon fixation using a process-based plant growth model: a case study of Fagus crenata grown under different soil nutrient levels. Sci Total Environ 716:137008. https://doi.org/10.1016/j.scitotenv. 2020.137008 
Kitao M, Komatsu M, Yazaki K, Kitaoka S, Tobita H (2015) Growth overcompensation against $\mathrm{O}_{3}$ exposure in two Japanese oak species, Quercus mongolica var. crispula and Quercus serrata, grown under elevated $\mathrm{CO}_{2}$. Environ Pollut 206:133-141. https:// doi.org/10.1016/j.envpol.2015.06.034

Koike T, Watanabe M, Hoshika Y, Kitao M, Matsumura H, Funada R, Izuta T (2013) Effects of ozone on forest ecosystems in east and Southeast Asia. In: Matyssek R, Clarke N, Cudlin P, Mikkelsen TN, Tuovinen J-P, Wieser G, Paoletti E (eds) Climate change, air pollution and global challenges: understanding and perspectives from forest research. Elsevier, Oxford, pp 371-390

Kopp RF, Smart LB, Maynard CA, Isebrands JG, Tuskan GA, Abrahamson LP (2001) The development of improved willow clones for eastern North America. For Chron 77:287-292. https://doi. org/10.5558/tfc 77287-2

Kume A, Numata S, Watanabe K, Honoki H, Nakajima H, Ishima M (2009) Influence of air pollution on the mountain forests along the Tateyama-Kurobe Alpine route. Ecol Res 24:821-830. https://doi.org/10.1007/s11284-008-0557-2

Li P, Feng Z, Catalayud V, Yuan X, Xu Y, Paoletti E (2017) A metaanalysis on growth, physiological, and biochemical responses of woody species to ground-level ozone highlights the role of plant functional types. Plant Cell Environ 40:2369-2380. https://doi. org/10.1111/pce.13043

Li K, Jacob DJ, Liao H, Qiu Y, Shen L, Zhai S, Bates KH, Sulprizio MP, Song S, Lu X, Zhang Q, Zheng B, Zhang Y, Zhang J, Lee HC, Kuk SK (2021) Ozone pollution in the North China Plain spreading into the late-winter haze season. Proc Natl Acad Sci U S A 118:e2015797118. https://doi.org/10.1073/pnas.2015797118

Lichtenthaler HK (1987) [34] Chlorophylls and carotenoids: pigments of photosynthetic biomembranes. Methods Enzymol 148:350-382

Liu C, Zhang L, Wen Y, Shi K (2021) Sensitivity analysis of $\mathrm{O}_{3}$ formation to its precursors-Multifractal approach. Atmos Environ 251:118275. https://doi.org/10.1016/j.atmosenv.2021.118275

Long SP, Bernacchi CJ (2003) Gas exchange measurements, what can they tell us about the underlying limitations to photosynthesis? Procedures and sources of error. J Exp Bot 54:2393-2401. https://doi.org/10.1093/jxb/erg262

Lumme I, Tormala T (1988) Selection of fast-growing willow (Salix spp.) clones for short- rotation forestry on mined peatlands in northern Finland. Silva Fenn 22:67-88. https://doi.org/10.14214/ sf.a15499

Manning W, Paoletti E, Sandermann H, Ernst D (2011) Ethylenediurea (EDU): a research tool for assessment and verification of the effects of ground level ozone on plants under natural conditions. Environ Pollut 159:3283-3293. https://doi.org/10.1016/j.envpol. 2011.07.005

Marschner H (2012) Marschner's mineral nutrition of higher plants, 3rd edn. Academic Press, USA, p 672

Maruyama Y, Mori S, Kitao M, Tobita H, Koike T (2002) Effects of fertilization on photosynthetic traits and yield of two willow species. Jpn J for Environ 44:71-75. https://doi.org/10.18922/ jjfe.44.2_71

Masui N, Agathokleous E, Mochizuki T, Tani A, Matsuura H, Koike $\mathrm{T}$ (2021) Ozone disrupts the communication between plants and insects in urban and suburban areas: an updated insight on plant volatiles. J for Res 32:1337-1349. https://doi.org/10.1007/ S11676-020-01287-4

Mola-Yudego B, González-Olabarria JR (2010) Mapping the expansion and distribution of willow plantations for bioenergy in Sweden: lessons to be learned about the spread of energy crops. Biomass Bioenerg 34:442-448. https://doi.org/10.1016/j.biombioe.2009. 12.008

Mola-Yudego B, Pelkonen P (2008) The effects of policy incentives in the adoption of willow short rotation coppice for bioenergy in
Sweden. Energy Policy 36:3062-3068. https://doi.org/10.1016/j. enpol.2008.03.036

Nagashima T, Sudo K, Akimoto H, Kurokawa J, Ohara T (2017) Longterm change in the source contribution to surface ozone over Japan. Atmos Chem Phys 17:8231-8246. https://doi.org/10.5194/ acp-17-8231-2017

Niiyama K (1987) Distribution of salicaceous species and soil texture of habitats along the Ishikari River. Jpn J Ecol 37:163-174. https://doi.org/10.18960/seitai.37.3_163

Nogueira ML, Carvalho MEA, Ferreira JMM, Bressanin LA, Piotto KDB, Marques DN, Barbosa S, Azevedo RA (2021) Cadmiuminduced transgenerational effects on tomato plants: a gift from parents to progenies. Sci Total Environ 789:147885. https://doi. org/10.1016/j.scitotenv.2021.147885

Nordborg M, Berndes G, Dimitriou I, Henriksson A, Mola-Yudego B, Rosenqvist H (2018) Energy analysis of willow production for bioenergy in Sweden. Renew Sustain Energy Rev 93:473-482. https://doi.org/10.1016/j.rser.2018.05.045

Oksanen E (2003) Physiological responses of birch (Betula pendula) to ozone: a comparison between open-soil-grown trees exposed for six growing seasons and potted seedlings exposed for one season. Tree Physiol 23:603-614. https://doi.org/10.1093/treep hys/23.9.603

Oksanen E, Pandey V, Pandey AK, Keski-Saari S, Kontunen-Soppela $S$, Sharma C (2013) Impacts of increasing ozone on Indian plants. Environ Pollut 177:189-200. https://doi.org/10.1016/j. envpol.2013.02.010

Onoda Y, Wright IJ, Evans JR, Hikosaka K, Kitajima K, Niinemets Ü, Poorter H, Tosens T, Westoby M (2017) Physiological and structural tradeoffs underlying the leaf economics spectrum. New Phytol 214:1447-1463. https://doi.org/10.1111/nph.14496

Pandey AK, Majumder B, Keski-Saari S, Kontunen-Soppela S, Mishra A, Sahu N, Pandey V, Oksanen E (2015) Searching for common responsive parameters for ozone tolerance in 18 rice cultivars in India: results from ethylenediurea studies. Sci Total Environ 532:230-238. https://doi.org/10.1016/j.scitotenv.2015.05.040

Pandey AKAK, Majumder B, Keski-Saari S, Kontunen-Soppela S, Pandey V, Oksanen E (2019) High variation in resource allocation strategies among 11 Indian wheat (Triticum aestivum) cultivars growing in high ozone environment. Climate 7:23. https://doi.org/10.3390/cli7020023

Paoletti E (2006) Impact of ozone on Mediterranean forests: a review. Environ Pollut 144:463-474. https://doi.org/10.1016/j. envpol.2005.12.051

Paoletti E, Contran N, Manning W, Ferrara AM (2009) Use of the antiozonant ethylenediurea (EDU) in Italy: verification of the effects of ambient ozone on crop plants and trees and investigation of EDU's mode of action. Environ Pollut 157:1453-1460. https://doi.org/10.1016/j.envpol.2008.09.021

Paoletti E, Castagna A, Ederli L, Pasqualini S, Ranieri A, Manning WJ (2014) Gene expression in snapbeans exposed to ozone and protected by ethylenediurea. Environ Pollut 193:1-5. https:// doi.org/10.1016/j.envpol.2014.06.001

Pellegrini E (2014) PSII photochemistry is the primary target of oxidative stress imposed by ozone in Tilia americana. Urban for Urban Green 13:94-102. https://doi.org/10.1016/j.ufug. 2013.10.006

Plucknett DL, Evenson JP, Sanford WG (1970) Ratoon cropping. Adv Agron 22:285-330. https://doi.org/10.1016/S0065-2113(08) 60271-0

Poorter H, Niinemets Ü, Poorter L, Wright IJ, Villar R (2009) Causes and consequences of variation in leaf mass per area (LMA): a meta-analysis. New Phytol 182:565-588. https://doi.org/10. 1111/j.1469-8137.2009.02830.x

Proietti C, Fornasier MF, Sicard P, Anav A, Paoletti E, De Marco A (2021) Trends in tropospheric ozone concentrations and forest 
impact metrics in Europe over the time period 2000-2014. J for Res 32:543-555. https://doi.org/10.1007/s11676-020-01226-3

Querol X, Massagué J, Alastuey A, Moreno T, Gangoiti G, Mantilla E, Duéguez JJ, Escudero M, Monfort E, Pérez García-Pando C, Petetin H, Jorba O, Vázquez V, de la Rosa J, Campos A, Muñóz M, Monge S, Hervás M, Javato R, Cornide MJ (2021) Lessons from the COVID-19 air pollution decrease in Spain: now what? Sci Total Environ 779:146380-146380. https://doi.org/10.1016/j. scitotenv.2021.146380

Sacchelli S, Carrari E, Paoletti E, Anav A, Hoshika Y, Sicard P, Screpanti A, Chirici G, Cocozza C, De Marco A (2021) Economic impacts of ambient ozone pollution on wood production in Italy. Sci Rep 11:154. https://doi.org/10.1038/s41598-020-80516-6

Sato T, Shimoda Y, Matsuda K, Tanaka A, Ito H (2018) Mg-dechelation of chlorophyll $a$ by Stay-Green activates chlorophyll $b$ degradation through expressing Non-Yellow Coloring 1 in Arabidopsis thaliana. J Plant Physiol 222:94-102. https://doi.org/10.1016/j. jplph.2018.01.010

Shang B, Feng Z, Li P, Calatayud V (2018) Elevated ozone affects C, $\mathrm{N}$ and $\mathrm{P}$ ecological stoichiometry and nutrient resorption of two poplar clones. Environ Pollut 234:136-144. https://doi.org/10. 1016/j.envpol.2017.11.056

Shi C, Watanabe T, Koike T (2017) Leaf stoichiometry of deciduous tree species in different soils exposed to free-air $\mathrm{O}_{3}$ enrichment over two growing seasons. Environ Exp Bot 138:148-163. https://doi.org/10.1016/j.envexpbot.2017.03.012

Shimoda Y, Ito H, Tanaka A (2016) Arabidopsis STAY-GREEN, Mendel's green cotyledon gene, encodes magnesium-dechelatase. Plant Cell 28:2147-2160. https://doi.org/10.1105/tpc.16.00428

Shinano T, Lei TT, Kawamukai T, Inoue MT, Koike T, Tadano T (1996) Dimethylsulfoxide method for the extraction of chlorophylls $a$ and $b$ from the leaves of wheat, field bean, dwarf bamboo, and oak. Photosynthetica 32:409-415

Sicard P (2021) Ground-level ozone over time: an observation-based global overview. Curr Opin Environ Sci Heal 19:100226. https:// doi.org/10.1016/j.coesh.2020.100226

Sicard P, Anav A, De Marco A, Paoletti E (2017) Projected global tropospheric ozone impacts on vegetation under different emission and climate scenarios. Atmos Chem Phys Discuss 17:1217712196. https://doi.org/10.5194/acp-2017-74

Sicard P, De Marco A, Agathokleous E, Feng Z, Xu X, Paoletti E, Diéguez Rodriguez JJ, Calatayud V (2020) Amplified ozone pollution in cities during the COVID-19 lockdown. Sci Total Environ 735:139542. https://doi.org/10.1016/j.scitotenv.2020.139542

Singh AA, Singh S, Agrawal M, Agrawal SB (2015) Assessment of ethylene diurea-induced protection in plants against ozone phytotoxicity. Rev Environ Contam Toxicol 233:129-184. https:// doi.org/10.1007/978-3-319-10479-9_4

Sperdouli I, Andreadis S, Moustaka J, Panteris E, Tsaballa A, Moustakas M (2021) Changes in light energy utilization in photosystem II and reactive oxygen species generation in potato leaves by the pinworm Tuta absoluta. Molecules 26:2984. https://doi.org/10. 3390/molecules26102984
Singh S, Singh P, Agrawal SB, Agrawal M (2018) Use of Ethylenediurea (EDU) in identifying indicator cultivars of Indian clover against ambient ozone. Ecotoxicol Environ Saf 147:1046-1055. https://doi.org/10.1016/j.ecoenv.2017.09.068

Tiwari S (2017) Ethylenediurea as a potential tool in evaluating ozone phytotoxicity: a review study on physiological, biochemical and morphological responses of plants. Environ Sci Pollut Res 24:14019-14039. https://doi.org/10.1007/s11356-017-8859-y

Tobita H, Komatsu M, Harayama H, Yazaki K, Kitaoka S, Kitao M (2019) Effects of combined $\mathrm{CO}_{2}$ and $\mathrm{O}_{3}$ exposures on net $\mathrm{CO}_{2}$ assimilation and biomass allocation in seedlings of the latesuccessional Fagus Crenata. Climate 7:117. https://doi.org/10. 3390/cli7100117

Ueno AC, Gundel PE, Ghersa CM, Demkura PV, Card SD, Mace WJ, Martínez-Ghersa MA (2020) Ontogenetic and trans-generational dynamics of a vertically transmitted fungal symbiont in an annual host plant in ozone-polluted settings. Plant Cell Environ 43:2540-2550. https://doi.org/10.1111/pce.13859

Ueno AC, Gundel PE, Molina-Montenegro MA, Ramos P, Ghersa CM, Martínez-Ghersa MA (2021) Getting ready for the ozone battle: vertically transmitted fungal endophytes have transgenerational positive effects in plants. Plant Cell Environ 44:2716-2728. https://doi.org/10.1111/pce.14047

Vlachojannis JE, Cameron M, Chrubasik S (2009) A systematic review on the effectiveness of willow bark for musculoskeletal pain. Phyther Res 23:897-900. https://doi.org/10.1002/ptr.2747

Volk TA, Abrahamson LP, Nowak CA, Smart LB, Tharakan PJ, White EH (2006) The development of short-rotation willow in the northeastern United States for bioenergy and bioproducts, agroforestry and phytoremediation. Biomass Bioenerg 30:715-727. https://doi.org/10.1016/j.biombioe.2006.03.001

Wan W, Manning WJ, Wang X, Zhang H, Sun X, Zhang Q (2014) Ozone and ozone injury on plants in and around Beijing, China. Environ Pollut 191:215-222. https://doi.org/10.1016/j.envpol. 2014.02.035

Wang L, Feng Z, Schjoerring JK (2013) Effects of elevated atmospheric $\mathrm{CO}_{2}$ on physiology and yield of wheat (Triticum aestivum L.): a meta-analytic test of current hypotheses. Agr Ecosyst Environ 178:57-63. https://doi.org/10.1016/j.agee.2013.06.013

Wang W, He A, Jiang G, Sun H, Jiang M, Man J, Ling X, Cui K, Huang J, Peng S, Nie L (2020) Ratoon rice technology: a green and resource-efficient way for rice production. Adv Agron 159:135167. https://doi.org/10.1016/bs.agron.2019.07.006

Yuan X, Calatayud V, Jiang L, Manning WJ, Hayes F, Tian Y, Feng Z (2015) Assessing the effects of ambient ozone in China on snap bean genotypes by using ethylenediurea (EDU). Environ Pollut 205:199-208. https://doi.org/10.1016/j.envpol.2015.05.043

Publisher's Note Springer Nature remains neutral with regard to jurisdictional claims in published maps and institutional affiliations. 